\title{
Cannabis and Psychosis: A Review of the Risk Factors Involved
}

\author{
Mohamed Ben Amar \\ Substance Abuse Program, Faculty of Continuing Education, Université de Montréal, Montréal, Canada \\ Email: mohamed.ben.amar@umontreal.ca
}

How to cite this paper: Ben Amar, M. (2020) Cannabis and Psychosis: A Review of the Risk Factors Involved. American Journal of Plant Sciences, 11, 1949-1990. https://doi.org/10.4236/ajps.2020.1112139

Received: August 10, 2020

Accepted: December 11, 2020

Published: December 14, 2020

Copyright (C) 2020 by author(s) and Scientific Research Publishing Inc. This work is licensed under the Creative Commons Attribution International License (CC BY 4.0).

http://creativecommons.org/licenses/by/4.0/

\begin{abstract}
Abundant literature suggests the hypothesis that cannabis use leads to the onset of psychotic symptoms. However, the nature of the association and the causal link remain controversial. This review aims to identify the risk factors involved in the etiopathogenesis of psychosis or psychotic features. Our electronic search found 1653 studies published until March $1^{\text {st }} 2020$. Longitudinal studies and literature reviews were selected if they addressed specifically the issues of the cannabis/psychosis relationship and the eventual risk factors involved. Our systematic review identified six potential risk factors involved in the association. They are, in decreasing importance, the dose-response relationship (quantity, frequency and duration of cannabis use), the early age of cannabis consumption, genetic susceptibility, childhood trauma, cigarette smoking and urban environment. In contrast, a significant inverse relationship exists between cannabidiol (CBD) and psychosis: cannabidiol is associated with less psychotic symptoms and manifests antipsychotic properties. Further studies are needed to establish a clear causal relationship between cannabis and psychosis and to identify the qualitative and quantitative contribution of specific risk factors on its onset and sustainability.
\end{abstract}

\section{Keywords}

Cannabis, Marijuana, Hashish, Psychosis, Schizophrenia, Risk Factors

\section{Introduction}

Cannabis is the most widely used drug in the world. According to the United Nations Office on Drugs and Crime, the number of cannabis consumers worldwide was estimated in 2018 to be 192 million users, with the highest prevalence been among young people [1]. 
Cannabis contains 565 known chemicals, of which 144 are grouped under the name cannabinoids. The major psychoactive ingredient of cannabis is delta 9-tetrahydrocannabinol, commonly known as THC. Other cannabinoids present in Indian hemp include delta 8-tetrahydrocannabinol $\left(\triangle^{8} \mathrm{THC}\right)$, cannabidiol $(\mathrm{CBD})$, cannabinol $(\mathrm{CBN})$, cannabicyclol $(\mathrm{CBL})$, cannabichromene $(\mathrm{CBC})$ and cannabigerol (CBG) [2] [3].

Cannabinoids exert some of their actions by binding to specific receptors: the CB1 cannabinoid receptors, discovered by Devane et al. in 1988 [4], then cloned by Matsuda et al. in 1990 [5] and the CB2 cannabinoid receptors identified by Munro et al. in 1993 [6].

Growing evidence supports the importance of the therapeutic potential of cannabis and cannabinoids. More than 250 controlled clinical trials have demonstrated their efficacy in a dozen pathologies [3] [7]-[12]. However, the therapeutic benefits of cannabis and some cannabinoids are mitigated by their eventual ability to trigger psychosis. The role of cannabis in the etiology, evolution and clinical expression of chronic psychoses is currently a topic of heated debate in the scientific community and the causal relationship remains controversial [12]-[21].

The review of the literature illustrates that the potential link between cannabis use and chronic psychosis falls into three broad categories [22]:

1) The first group of studies suggests a causal relationship between cannabis consumption and diagnosed psychosis [23] [24];

2) The second group suggests that long-term cannabis consumption may increase the number of psychotic symptoms without increasing the number of diagnoses of psychosis itself [25] [26] [27] [28] [29];

3) The third group of studies shows no causal relationship between cannabis use and psychosis [13] [30].

The current study is conducted to identify the risk factors involved in the development of psychosis or psychotic features and to clarify their contribution to its onset and sustainability.

\section{Methods}

A systematic search was performed in PubMed and PsycInfo using the criteria "cannabis or marijuana or haschish" AND "schizophrenia or psychosis". This search identified 1653 studies published between January 1, 1962 and February 1' 2020. For this study, longitudinal studies as well as literature reviews were selected according to the following inclusion criteria:

1) They had to address specifically the issue of the causal nature of the cannabis-psychosis relationship, whether it is present, absent or controversial;

2) They had to address and analyse the eventual risk factors involved or susceptible to contribute to the development of psychosis;

3) They had to have been published between January 1, 1962 and March 1, 2020 . 
Articles related to the potential explanations of the cannabis-psychosis relationship and other mechanisms or evidence supporting or refuting the causal link were also selected for review.

\section{Results}

Our literature review has found six risk factors involved in the development of psychosis or psychotic features. They are in decreasing importance the dose-response relationship (quantity, frequency and duration of cannabis use), the early age of cannabis consumption, genetic susceptibility, childhood trauma, cigarette smoking and urban environment.

\subsection{Dose-Response Relationship (Quantity, Potency, Frequency and Duration of Cannabis Use)}

A dose-response relationship has clearly been established between the amounts of cannabis consumed and the likelihood of developing psychosis. Indeed, the risk of manifesting psychosis or psychotic symptoms increases with the quantity, the potency, the frequency and the duration of cannabis use [23] [24] [29] [31]-[59].

Some reviews have demonstrated that cannabis use is associated with roughly a two-fold increased risk of developing psychosis [60] [61] [62]. This risk increases almost three-fold when high-potency cannabis is consumed [63].

Cross sectional studies have demonstrated that the frequency of cannabis consumption is correlated with the appearance of psychotic-like experiences (PLEs), as measured by the Community Assessment of Psychic Experiences (CAPE). This correlation was observed in France among 571 female undergraduates with a mean age of 19.8 years and a range of 18 - 51 years [64] and in Greece among a representative sample of 3500 youngsters aged 19 on average [65]. In both studies, cannabis use with a higher lifetime frequency was associated with all positive symptom dimensions of schizophrenia, meaning first rank symptoms dimensions of schizophrenia, grandiosity, hallucinations and paranoia [64] [65].

In contrast, an Australian study carried on 880 young people whose mean age was 15 years (range: 13 - 19 years, $\mathrm{SD}=0.4$ ) revealed that regular (weekly ever) cannabis use was not associated with any psychotic like experience (PLE) variable. In addition, less frequent cannabis consumption in the last year was more strongly correlated with PLEs than frequent ( $\geq$ monthly) cannabis use [66].

Another Australian study conducted on 3801 subjects (among which 1806 were males), ranging from 18 to 23 years, with a mean age of 20.1 years (SD = 0.90 ), found that among those with duration of cannabis use since first consumption was 6 or more years, there was a significantly increased risk of three psychosis-related outcomes [38]:

- Nonaffective psychosis: adjusted odds ratio $=2.2 ; 95 \%$ confidence interval $=$ $1.1-4.5$;

- Hallucinations: adjusted odds ratio $=2.8 ; 95 \%$ confidence interval $=1.9-4.1$; 
- Being the highest quartile of the Peter's Delusions Inventory score: adjusted odds ratio $=4.2 ; 95 \%$ confidence interval $=4.2-5.8$.

The authors also demonstrated that within sibling pairs, the duration since first cannabis use and higher scores on the Peter's Delusions Inventory remained significantly correlated [38].

The work of McGrath et al. [38] illustrates that quantities of cannabis consumption, frequency of administration and longer duration since first cannabis use are associated with multiple psychosis-related outcomes in young adults and more frequently in children and adolescents between 12 to 18 years of age.

In Ireland, researchers conducted a study on 1049 students attending the National University of Ireland which revealed that more frequent cannabis use was independently correlated with greater intensity of positive, negative and depressive psychotic symptoms [67]. The authors also found that the earlier the age of onset of cannabis use, the more positive psychotic symptoms were reported [67].

In the Netherlands, Van Gastel et al. [68] carried on a cohort study of 4552 youngsters aged 12 - 16 years, all secondary school students and 50\% females, in which they categorized three levels of last year cannabis users: experimental users (once or twice during the last year), regular users (between 3 to 39 times during the last year), and heavy users (40 times or more during the last year). The researchers found a dose-response relationship for cannabis use and positive psychotic experiences, with an increase in these experiences for higher frequencies of use [68]. This observation, as well as the fact this correlation remains after controlling for an elaborate set of confounders, support the assertion that the quantity, frequency and duration of cannabis consumption represent a risk factor for the development of psychosis [68].

In the United States, a team of researchers conducted a large population-based epidemiologic study on 34,653 American adults. It revealed that the prevalence of both psychosis and schizotypal personality disorder (SPD) increased significantly with greater cannabis use, in a dose-dependent manner. The associations between cannabis use and psychosis were 1.27 (95\% confidence interval $=1.03$ 1.57) for lifetime cannabis use, $1.79(95 \%$ confidence interval $=1.35-2.38)$ for lifetime cannabis abuse, and 3.69 (95\% confidence interval $=2.49-5.47)$ for lifetime cannabis dependence [69]. In addition, compared to non-users, cannabis consumers had a significantly elevated prevalence of schizotypal personality disorders (SPD) symptoms in all domains of schizophrenia, namely positive/cognitive-perceptual, negative/interpersonal, and disorganized behaviours [69].

Finally, a random-effects meta-analysis performed recently has demonstrated that cannabis use is predictive of transition to psychosis not in lifetime cannabis consumers but only in individuals who met criteria for cannabis abuse or dependence [62]. This study seems to confirm the dose-response relationship between cannabis consumption and transition to the first episode of psychosis [62].

In summary, with a few exceptions contradicting the assertion, heavy cannabis use is suspected to be correlated with the appearance of both psychotic 
symptoms and schizophrenia.

\subsection{Early Age of Cannabis Consumption}

Various studies carried worldwide suggest that early onset of cannabis use increases the likelihood of developing psychosis in adulthood [44] [55] [57] [70]-[79].

An Australian investigation demonstrated that children and adolescents who consumed cannabis prior to the age of 15 were 4.5 times more likely to have a diagnosis of schizophreniform psychosis at the age of 26 [25].

This observation was confirmed in adolescents of Greece [65] and Trinidad [80], suggesting that the adolescent brain is more sensitive to the exposure of cannabis [81].

In a large Australian community sample of 880 adolescents whose mean age was 15 years (range: 13 - 19 years; $\mathrm{SD}=0.4$ ), researchers found that early onset of cannabis use was associated with a greater risk of developing psychotic-like experiences (PLEs) and psychosis [66].

A study of 17,698 Dutch-speaking adolescents and young adults (18 - 25 years), with a mean age of 21 years, showed that participants who started to use cannabis before the age of 12 years had an adjusted odds ratio of 3.1 for the highest $10 \%$ of scores on psychotic experiences compared with individuals of 15 - 18 years. In contrast, initial cannabis use after the age of 18 was not associated with an increased score on psychotic experiences. Negative symptoms were correlated with cannabis consumption at the age of 12 years (odds ratio $=1.7 ; 95 \%$ confidence interval $=1.1-2.5$ ) and also before the age of 15 years (odds ratio $=$ 1.1; $95 \%$ confidence interval $=1.0-1.3$ ). In contrast, depressive symptoms were not associated with a young initial age of cannabis use [74].

Moreover, cannabis onset after the age of 18 years was not linked to an increased odds ratio for negative symptoms but individuals who started cannabis after the age of 20 years experienced more depressive symptoms that the reference group (odds ratio $=1.4 ; 95 \%$ confidence interval $=1.0-1.8$ ) [74].

The authors suggested that an increased vulnerability to THC during critical phases of brain maturation, as early puberty, could explain the specific association between psychotic experiences and a young initial age of THC exposure [74].

In a cohort of 4552 Dutch participants, aged 12 - 16 years (all secondary school students and 50\% females), Van Gastel et al. [68] showed that cannabis use among early adolescents of this age is related to subclinical positive symptoms of psychosis, even when an elaborate set of confounders is taken into account $(\beta=0.0088 ; \mathrm{p}=0.000)$. A significant relationship between cannabis use and age of developing positive experiences of psychosis was apparent $(\beta=0.081$; $\mathrm{p}=0.000$ ), demonstrating that this association is strongest for the youngest children and remains present even after abstaining from cannabis for at least one year [68]. 
The authors suggested that a window of vulnerability exists at an early age, stating that cannabis use at a young age during development stages of the brain may lead to persisting psychotic symptoms and eventually even to florid psychosis [68].

Another Dutch study involving a large population sample of 2120 adolescents has demonstrated that cannabis use at age 16 predicts psychosis vulnerability at age $19(Z=2.6 ; \mathrm{p}<0.05)$ and that psychosis vulnerability at ages $13(\mathrm{Z}=2.0 ; \mathrm{p}<$ $0.05)$ and $16(Z=3.0 ; p<0.05)$ predicts cannabis use at, respectively, ages 16 and 19 [82].

The authors concluded that cannabis consumption predicts psychosis vulnerability in adolescents and vice-versa, suggesting that there is a bidirectional causal association between the two [82].

A European study conducted in England, Finland, Germany and the Netherlands on 245 individuals with a clinical high risk of psychosis found that an early onset of cannabis use is associated with an early appearance of a range of psychotic symptoms in cannabis consumers presenting a clinical high risk of developing psychosis [83].

The authors demonstrated that the association could not be attributed to gender, premorbid social adjustment, premorbid academic adjustment or alcohol use disorder. Furthermore, they showed that the most robust associations were found between age of onset of cannabis use and age of appearance of anxiety, derealization, and weakness of thinking and concentration [83].

In addition, researcher's results indicated that most participants started the use of cannabis before the appearance of the nine examined psychotic symptoms [83].

A team of Spanish and British researchers has evaluated the concomitant impact of daily cannabis use versus non-daily cannabis use as well as the impact of early age of cannabis use on specific profiles of subclinical psychotic symptoms measured by the CAPE [42]. In a cohort of 241 Spanish cannabis users, the authors found that 31 daily cannabis users (44\%) who started to consume cannabis before the age of 17 reported a high presence in first-rank dimension compared to 7 non-daily cannabis users (13\%) who began use before 17 years of age $(\mathrm{p}=$ 0.0001). This difference remained statistically significant after adjustment for age, sex, social exclusion, alcohol and other drugs (odds ratio $=9.5 ; 95 \%$ confidence interval $=2.8-3.6 ; \mathrm{p}=0.0001$ ).

In contrast, the authors did not find differences between daily cannabis users and non-daily cannabis users when the subjects started to smoke cannabis after the age of 16 following adjustment by sex, age, social exclusion, alcohol and other drugs $(7(15 \%)$ versus $3(16 \%)$; odds ratio $=0.42 ; 95 \%$ confidence interval $=$ $0.02-0.82 ; \mathrm{p}=0.57$ adjusted by sex, age, social exclusion, alcohol and other drugs [42].

Similarly, 22 daily cannabis users (31\%) who started smoking cannabis before the age of 17 reported a higher presence of voices experience as opposed to 3 
non-daily cannabis users (6\%) who started using cannabis before the age of 17 ( $\mathrm{p}$ $=0.0001$ ). This difference remained statistically significant after adjustment by age, sex, social exclusion, alcohol and other drugs (odds ratio $=8.5$; 95\% confidence interval $=2.0-35.3 ; \mathrm{p}=0.003$ ). By opposition, there was no difference between daily cannabis users and non-daily cannabis users who started smoking cannabis after the age of 16, adjusted by sex, age, social exclusion, alcohol and other drugs $(5(11 \%)$ versus $2(11 \%)$; odds ratio $=0.16 ; 95 \%$ confidence interval $=0.06-4.3 ; \mathrm{p}=0.28$ adjusted by sex, age, social exclusion, alcohol and other drugs) [42].

In contrast, among subjects who started smoking cannabis before the age of 17 , there were no differences between daily cannabis users and non-daily cannabis users in mania and paranoid dimensions adjusted by age, sex, social exclusion, alcohol and other drugs. Among those who started consuming cannabis at the age of 17 or more, there were no differences between daily cannabis users and non-daily cannabis users in mania and paranoid dimensions [42].

By exploring specific dimensions of psychosis, the results of Ruiz-Veguilla et al. suggest that early age of cannabis use has no impact on mania and paranoid expressions, no matter the quantity of cannabis consumed, but concomitant early cannabis use and daily cannabis use affect adversely first-rank dimensions and voices experiences of psychosis [42].

After examining their results, Ruiz-Veguilla et al. [42] also suggested that an enduring form of neural adaptation may occur in dopaminergic neurons after subchronic cannabis consumption at a young age. They postulated, in accordance with the works of Spauwen et al., [84] and Bossong and Niesink [85], that early cannabis use modifies the development of neurotransmitter systems which conducts to a sensitization to cannabis use in adulthood through diverse effects on the dopamine function [42] [84] [85].

If we analyse the overall results of Ruiz-Veguilla et al., we can infer that cannabis use during puberty combined with its heavy consumption can lead to the development of first-rank dimension and voices experience of psychosis, but has no impact on mania and paranoid expressions of the disease. While their study demonstrates that cannabis use during puberty combined with heavy use increases the likelihood of developing some specific symptoms of psychosis, it does not evaluate separately the respective contributions of early age and heavy use of cannabis on the presence or absence of the different clusters of symptoms of psychosis [42].

The Australian study conducted by McGrath et al. [38] and previously commented provides further support for the hypothesis that early cannabis consumption is a risk factor for psychosis-related outcomes in young adults.

Apart from the works mentioned above, the review of the scientific literature reveals that prospective cohort studies demonstrate that an early onset of cannabis consumption is correlated with an increased risk of psychosis related outcomes [23] [24] [25] [26] [70] [71] [72] [75] [86] [87]. 


\subsection{Genetic Susceptibility}

Cannabis abuse might increase the risk for psychosis by modifying the genetic expression of the CB1 receptor [22]. In fact, studies have shown a correlation between genetic polymorphism of the CB1 receptor and schizophrenia, suggesting that gene variants may confer susceptibility to this disorder [29] [32] [60] [77] [88] [89] [90] [91] [92].

Catechol-0-methyltransferase (COMT) is an enzyme which plays an important role in the degradation of dopamine in the brain [93]. It contains a functional polymorphism in its sequence, COMT-Val ${ }^{158}$ Met, that directly influences enzyme activity and results in two common variants of the enzyme: Val and Met [94] [95]. The Val/Val genotype has a 40\% higher COMT enzyme activity in the brain than individuals with the Met/Met genotype. The Val/Val genotype results in a combination of increased concentrations of dopamine in the mesolimbic regions and subsequently lower dopamine levels in the prefrontal cortex [96] [97]. Individuals who have the Met/Met genotype manifest the lowest COMT activity, while heterozygotes have an intermediate activity because the two alleles are codominant [94] [98].

The increased dopaminergic activity in the mesolimbic areas is thought to be associated with subclinical positive psychotic symptoms [97] [99] [100] [101].

Chronic cannabis consumption results in an increase in dopamine concentrations in the mesolimbic regions of the brain and a decrease in dopamine concentrations in the prefrontal cortex which mimics the neurochemical state observed in schizophrenia [97] [102].

In the past ten years, several works have suggested that differential sensitivity to environmental stress produced by the $\mathrm{Val}^{158}$ Met polymorphism of the catechol-O-methyltransferase (COMT) gene, probably by interacting with other factors, might be responsible for increasing the risk to develop psychosis [103] [104] [105].

A genetic analysis conducted among New Zealand participants in the Dunedin cohort study demonstrated that the relationship between cannabis use and the risk of developing psychosis was moderated by a COMT gene polymorphism: cannabis users who first consumed cannabis prior to the age of 18 years and who carried the COMT Val/Val genotype were 10.9 times more likely to develop schizophreniform disorders at age 26, whereas individuals Met/Met homozygotes did not present such a risk (odds ratio $=1.1$ ) while exposed to cannabis use [106].

However, different studies have failed to replicate the findings of Caspi's team [101] [107]-[112]. Other studies reported the Caspi's interaction only in subgroups of individuals [113] [114].

Despite this discrepancy, several researchers have demonstrated that the $\mathrm{Val}^{158}$ Met polymorphism of the catechol-0-methyltransferase (COMT) gene moderates both the association between cannabis use and psychosis and the association between childhood trauma and schizotypal traits [93] [102] [114] [115] 


\section{[116] [117].}

Spanish investigators have demonstrated that variability in the COMT gene confers different neurobiological vulnerability to cannabis consumption in the risk of developing psychotic experiences (PEs), the milder forms of psychotic symptoms [93]. In accordance with previous works, the researchers concluded that Val carriers are more vulnerable to the psychosis-inducing effects of cannabis than Met/Met individuals, but only when exposed to childhood abuse [93]. The authors further suggested that sensitization mechanisms involving dopaminergic signalling may be underlying this gene-environment interaction [93].

Moreover, a Dutch study confirmed the COMT genetic association: weekly cannabis users had more severe positive psychotic symptoms if they were carriers of the COMT Val allele (Val/Met) and even more so if they were $\mathrm{Val} / \mathrm{Val}$ homozygotes [97].

In addition, a team of Dutch and British investigators has illustrated that a genetic variation in AKT 1 (a serine/threonine kinase) may mediate both short term and long term effects on psychosis expression associated with cannabis use, possibly through a mechanism of cannabinoid-regulated AKT 1/GSK-3 signalling downstream of the dopamine D2 receptor [110].

Finally, the same group of Dutch and British researchers conducted a sibling-control comparison which demonstrated that siblings (individuals who are genetically at higher risk for psychotic disorders, allowing for comparisons with a control group) display more than 15 times greater sensitivity to positive schizotypy associated with particularly current cannabis use determined by urinalysis (adjusted $\beta=0.197 ; \mathrm{p}<0.001$ ) than controls (adjusted $\beta=0.013 ; \mathrm{p}=0.036 ; \mathrm{p}$ interaction $=0.04$ ) and a similar difference in sensitivity to its effects on negative schizotypy (siblings: adjusted $\beta=0.0120 ; \mathrm{p}<0.001$; controls: $\beta=-0.008 ; \mathrm{p}=$ 0.87 ; $\mathrm{p}$ interaction $=0.03)$ [118].

Similarly, siblings exposed to cannabis resembled their patient relative nearly 10 times more closely in the positive psychotic dimension of the Community Assessment of Psychic Experiences (CAPE) (adjusted $\beta=0.278 ; \mathrm{p}<0.001$ ) compared with non-exposed siblings (adjusted $\beta=0.025 ; \mathrm{p}=0.12$; $\mathrm{p}$ interaction $<0.001$ ) [118].

No significant effect was apparent for the CAPE negative domain, although the association was directionally similar ( 2 times more resemblance; $p$ interaction $=0.17$ [118].

Based on cross-sibling, cross trait analyses, the authors suggested that the mechanism underlying these findings is an increased sensitivity to the psychotomimetic effects of THC in subjects with an increased familiar risk to cannabis exposure [118].

A cross-sectional study conducted on 918 Dutch individuals revealed that a functional polymorphism in the catechol-0-methyltransferase (COMT) gene may moderate the interaction between childhood trauma and cannabis use on psychotic experiences in the general population (Vinkers et al., 2013) [117]. Researchers suggested that the COMT Val ${ }^{158}$ Met polymorphism may constitute a 
genetic risk factor for psychotic symptoms in the context of combined exposure to childhood trauma and cannabis use. They confirmed in their study that childhood trauma is strongly associated with psychotic symptoms independently of cannabis and the COMT genotype [117] [119] [120] [121].

Finally, the work of Vinkers et al. could not provide information about the causality of the interaction between childhood trauma, cannabis and COMT on psychotic experiences due to the cross-sectional nature of the data [117].

On the other hand, it has been demonstrated that carriers of the AKT 1 rs 2494732 C genotype have an increased psychosis risk if they have a history of cannabis use, specially of daily use [40] [122] [123] or cannabis dependence [124].

This higher probability of developing psychosis is also observed with carriers of the DRD2 rs $1076560 \mathrm{~T}$ allele among cannabis consumers, especially in frequent users [123] [125].

Despite all this evidence, some studies have found no interaction between cannabis use and genetic susceptibility to psychosis [95] [126] [127].

\subsection{Childhood Trauma}

A vast body of scientific literature suggests that the experience of childhood trauma, physical or psychological, including bullying and sexual abuse, is a risk factor for the development of schizophrenia [119] [120] [128] [129] [130] [131] [132] or psychotic symptoms [70] [72] [75] [77] [84] [133]-[141].

In addition, exposure to a greater number of traumas is correlated with a higher risk of psychosis [84] [128]. Moreover, it has been demonstrated that childhood trauma increases the risk of substance abuse, including cannabis consumption, in adolescence and adulthood [142] [143] [144] [145].

Taken together, these strands of evidence point to the possibility that childhood trauma may play a role in the association between cannabis use and psychosis [146] [147] [148] [149].

All these observations raise the question of the causal link(s) and the direction (s) of the association: it is important to determine if child abuse, in different forms and circumstances, caused first the consumption of cannabis or induced primarily the appearance of psychosis or psychotic symptoms. It is also a matter of concern to know if cannabis is consumed to alleviate first the traumatic events of childhood or the symptoms of psychosis, or both situations simultaneously when they are concomitantly present.

Data on cannabis use and sexual trauma experiences from 5877 American citizens aged between 15 and 54 years revealed that the impact of sexual trauma on clinically assessed diagnoses of psychosis was statistically significant in individuals who used cannabis under 16 years (odds ratio $=11.96$; $95 \%$ confidence inter$\mathrm{val}=2.10-68.22 ; \mathrm{p}=0.01)$ but not for those who had not used cannabis under 16 years (adds ratio $=1.80 ; 95 \%$ confidence interval $=0.91-3.57 ; \mathrm{p}=0.09$ ). In fact, those who used cannabis under the age of 16 years and had also been sexually abused were almost 12 times more likely to receive a diagnosis of psychosis 
[147].

The authors stated that the mediating role of cannabis suggests that early cannabis use may increase the strength of the proposed trauma-psychosis relationship. They proposed that this correlation could be explained by both cannabis use and trauma acting indirectly on the dopaminergic system, as sexual traumas produce elevated cortisol levels which in turn are associated with dopamine activity [147].

The researchers also postulated that childhood abuse enhances an individual's vulnerability to psychotic symptoms and that cannabis use acts as an exacerbating agent heightening psychotic experience in those persons who have suffered abuse. Alternatively, cannabis consumption could be considered the vulnerability factor and childhood sexual abuse the environmental factor that increases the likelihood of psychosis [147]. Finally, the investigators suggested that exposure to a trauma followed by cannabis use (self-medication) and cannabis use followed by trauma produce significantly different likelihoods of psychosis [147].

An Irish study conducted on 211 adolescents aged between 12 and 15 years has revealed that those adolescents who had experienced childhood trauma were almost five times more likely to use cannabis (odds ratio $=4.86$; $95 \%$ confidence interval $=1.63-14.51 ; \mathrm{p}=0.005)$ than those who had experienced trauma. In addition, subjects who had experienced childhood trauma are also five times more likely to develop psychotic symptoms (odds ratio $=5.20$; $95 \%$ confidence interval $=1.58$ - 17.13; $\mathrm{p}=0.007$ ) [149].

The researchers also found that the joint presence of cannabis use and childhood trauma increased the likelihood of psychotic symptoms in adolescence to a much greater extent than would be expected if each risk factor was working independently [149].

In Australia, a 20-year follow-up study in young adults exposed to childhood trauma revealed that exposure to multiple traumas, rather than a single major trauma, increases the risk of later psychosis [150].

Based on the Adult Psychiatric Morbidity Survey conducted in England in 2007 among 7403 subjects whose mean age was 51.12 years $(S D=18.59)$, a multivariate analysis demonstrated that those who had experienced non-consensual sex in childhood were over six times (odds ratio $=6.10$ ) more likely to have had a diagnosis of psychosis compared with those who had not experienced this trauma. Individuals with a history of non-consensual sexual experience under 16 years and cannabis use were over seven times more likely (odds ratio $=7.84$; 95\% confidence interval $=1.63-37.67$ ) to have been diagnosed with psychosis compared with those without these experiences [151].

The multivariate analysis also indicated that subjects who were unemployed, depressed and who experienced sexual trauma (s) after the age of 16 years were more likely to have had a diagnosis of psychosis (odds ratios $=5.01,21.80$ and 2.07 , respectively). Researchers outlined the fact that the experience of non-consensual sex before the age of 16 years was independently predictive of psychosis diagnosis no matter the presence or absence of cannabis consumption [151]. 
They suggested that childhood trauma may be one of the more prevailing environmental agents in psychosis onset and development and that cannabis use among individuals diagnosed with psychosis may be attributable, in some cases, to their experiences of childhood trauma [151]. The authors also mentioned that those individuals who experienced both childhood sexual abuse and cannabis use, but who experienced their sexual trauma before they began consuming cannabis, were over four times more likely to have a diagnosis of psychosis. Alternatively, victims of childhood trauma may simply initiate and continue to use cannabis in a similar way to non-victims but could experience psychosis because an existing emotional, psychological and/or physical vulnerability, potentially attributable to their trauma, has been exacerbated [151].

Finally, the authors concluded that the interaction between cannabis use and childhood trauma suggests that being exposed to these two risk factors acts synergistically in the onset of psychosis and that childhood trauma may advance existing gene-environment conceptualizations of the cannabis-psychosis link [151].

The joint analysis of two independent population-based samples of the Greek National Perinatal Study $(\mathrm{n}=1636)$ and the Netherlands Mental Health Survey and Incidence Study (NEMESIS) $(\mathrm{n}=4842)$ revealed that a significant adjusted interaction between childhood trauma and later cannabis use was evident in both samples, indicating that the psychosis-inducing effects of cannabis were stronger in individuals exposed to earlier sexual or physical mistreatment [152]:

- Greek National Perinatal Study: test for interaction F $(2,1627)=4.18 ; \mathrm{p}=$ 0.02 ;

- NEMESIS: test for interaction $\mathrm{X}^{2}(3)=8.08 ; \mathrm{p}=0.04$.

As demonstrated in the work of Houston et al. [151], Konings et al. [152] confirmed in this study that cannabis use and trauma in childhood or early adolescence act synergistically, by a more than additive interaction on the same final common pathway to psychotic symptoms.

Researchers suggested that the psychosis-inducing effects of cannabis are moderated by an early experience of trauma and that a cross-sensitization between stress and cannabis is responsible in shaping the risk of psychotic outcomes [152]. The possible mechanism by which stress or cannabis use impact on psychosis risk is a sensitization involving an increase of the dopaminergic signaling in the mesolimbic system [153] [154] [155].

Hyperdopaminergia may be associated with psychosis [99] and the interaction between early life trauma and cannabis may increase the risk for psychosis by bringing about enduring sensitization to dopamine agonists [101] [152] [156].

Finally, the authors stated that their work is the first to demonstrate that even non-severe physical trauma can interact with cannabis on psychosis risk [152]. Their results confirm earlier findings that both cannabis and trauma not only affect psychotic illness but also impact on the broader extended psychosis phenotype in the general population, which represents behavior expression of liability to psychotic disorders [152]. However, they outline that their results do not 
provide information about to what degree the interaction between cannabis and maltreatment contributes to the onset of new psychotic symptoms or to the persistence of existing symptoms [152] [157].

Using data from the National Comorbidity Survey-Replication $(\mathrm{n}=2355)$, researchers in the United Kingdom obtained the following results [158]:

- Psychotic experiences that occurred before childhood sexual trauma significantly influenced adult psychosis symptomatology (psychosis pre-rape $\beta=$ 0.10 ; psychosis pre-sexual assault $\beta=0.23$ );

- Social phobia also conferred risk for adult psychosis $(\beta=0.07)$;

- Pre-trauma childhood psychopathology did not account for the interaction between childhood sexual trauma and cannabis use in a multivariable model;

- Childhood experiences of rape $(\beta=0.15)$ and an interaction between cannabis consumption and childhood sexual assault $(\beta=0.05)$ independently contributed to adult psychosis.

Consistent with previous works, Murphy et al. [158] stated that their findings illustrate that:

1) Childhood sexual trauma (rape) independently contributes to psychotic experiences;

2) The combined effect of childhood sexual trauma and cannabis use independently contributes to psychotic experiences;

3) Cannabis use is devoid of any independent risk for psychotic experiences.

As in the analysis of Houston et al. [151], the authors suggested that victims of childhood trauma may initiate and continue to use cannabis in a similar way to non-victims but manifest psychosis because an emotional, psychological and/or physical vulnerability, potentially attributable to trauma, has been exacerbated [151] [158].

Furthermore, researchers suggested that cannabis use is highly associated with a key source of risk for psychosis but does not influence psychosis itself, that it exacerbates another source of risk or moderates pre-existing risk or that it influences psychosis post-onset [158].

Finally, the investigators raised the possibility that social anxiety and interpersonal trauma history could potentiate the pharmacologic effects of cannabis consumption for some individuals, or vice versa, that cannabis use could intensify or amplify existing vulnerabilities or insecurities caused by traumatic experience (s) and ultimately lead to psychosis [158].

A three-year cohort study conducted in the Netherlands on individuals at average $(n=462)$ and high genetic risk $(n=810)$ revealed that childhood trauma represented the highest risk to develop psychotic disorders (odds ratio $=34.4$; $95 \%$ confidence interval $=4.4-267.4)$ compared to cannabis use (odds ratio $=$ $4.1 ; 95 \%$ confidence interval $=1.1-15.4)$, minority ethnic group $($ odds ratio $=$ 3.8 ; $95 \%$ confidence interval $=1.2-12.8$ ) and urban birth (odds ratio $=3.7 ; 95 \%$ confidence interval $=0.9-15.4$ ). The proportion of transitions in the population attributable to environmental and genetic risk ranged from $28 \%$ for minority ethnic group, $45 \%$ for urban birth, $50 \%$ for high-risk sibling status, $57 \%$ for 
cannabis use, and $86 \%$ for childhood trauma. Nine out of eleven transitions (82\%) were exposed to both genetic and environmental risk, compared to only $43 \%$ of non-transitions $(\mathrm{p}=0.03)$ [159].

In their analysis, researchers outlined the following facts [159]:

- All environmental risk factors were associated with transition to psychotic disorders, with the greatest effect, in terms of both relative and attributable risk, for childhood trauma;

- Exposure to environmental risk did not vary as a function of genetic high risk status, suggesting an absence of genetic control of environmental exposure or a gene-environment correlation;

- Exposure to both genetic and environmental risk factors is necessary for transition, which is compatible with underlying gene-environment interaction.

In a population-based household survey collected from 1680 individuals as part of the South East London Community Hearth Study, Morgan et al. [160] found a strong evidence that the odds of reporting a psychotic experience were higher in those who, during childhood, had:

1) Been physically abused: adjusted odds ratio $=2.7 ; 95 \%$ confidence interval $=1.62-2.89$; and

2) Been sexually abused: adjusted odds ratio $=2.13 ; 95 \%$ confidence interval $=$ $1.28-3.56$.

The majority (58\%) of those who reported sexual abuse also suffered from physical abuse. When both physical and sexual abuse were considered together, there was evidence that the association with psychotic experiences was highest for those exposed to both factors: adjusted odds ratio $=3.24$; $95 \%$ confidence interval $=1.68-6.25[160]$.

Researchers emphasized that there was a strong evidence that childhood trauma was correlated with an increased odds of later life events and cannabis use, and that there was evidence for synergistic effects of trauma and more tentatively $(p=0.07)$ recent cannabis use on odds of psychotic experiences, such that the odds were greatest in those exposed to trauma and either life events or cannabis in the past year. They also outlined that the impact of both life events, particularly recent events, and cannabis use on the likelihood of psychotic experiences depends, to a certain degree, on prior exposure to physical and sexual abuse. This is consistent with the hypothesis that childhood trauma creates in some individuals a vulnerability for psychotic experiences which unfolds itself in the event of exposure to further risk factors such as cannabis consumption [160].

Finally, a study conducted in Spain among 60 patient-sibling pairs, constituted by subjects with functional psychosis in the first five years of their illness matched with a non-psychotic sibling, demonstrated that after controlling for cannabis use and neuroticism, the odds of suffering psychosis for individuals who were afflicted with a childhood trauma were 7.3 times higher than the odds for persons who did not experience a childhood trauma (95\% confidence inter$\mathrm{val}=1.06-50.01 ; \mathrm{p}=0.04)[45]$. 
Of note, some researchers illustrated that neither lifetime cannabis use nor reported exposure to childhood trauma was correlated to psychotic disorders when the other risk factor was taken into account [39] [161]. It is the combination of the two risk factors that raises significantly the odds for developing psychosis by nearly three times (adjusted odds ratio $=2.94 ; 95 \%$ confidence interval $=1.44-6.02 ; \mathrm{p}=0.003[161]$.

\subsection{Cigarette Smoking}

Some longitudinal studies have found a dose-response relationship between cigarette smoking in adolescence and later psychotic symptoms in the general population [162] [163] [164] [165] [166]. Moreover, two cross-sectional investigations demonstrated a correlation between cigarette smoking and psychotic symptoms [167] [168]. On the other hand, it is estimated that between 70 à $85 \%$ of schizophrenic patients smoke cigarettes [169] [170].

These observations raise the two following questions:

1) To what extent the relationship between cannabis use and psychotic-like experiences (PLE) or delusional-like experiences (DLE) is influenced by cigarette smoking? [164];

2) What is the direction of causality between psychotic-like experiences (PLE) or delusional-like experiences (DLE) and the measures of cigarette use and cannabis use? [171].

An Australian study conducted on 8773 individuals aged between 16 and 85 years found that delusional-like experiences (DLEs), which are attenuated features of psychoses, were more likely to be present in everyday tobacco smokers or in individuals who started smoking at the age of 15 or earlier [171]. Researchers outlined that their findings were consistent with another previous work of a similar population sample in Australia [167] and demonstrated that an earlier age at onset of tobacco use and cannabis use disorders were significantly correlated with delusional-like experiences [171]. The authors were unable to establish the causal direction between delusional-like experiences and the measures of cigarette use and cannabis use because the study was cross-sectional [171].

In a sample of 1929 Dutch young adults aged 18 to 30 years, investigators demonstrated that cigarette smoking was as strongly associated as cannabis use with the frequency of psychotic-like experiences $(\beta=0.098$ and 0.079 respectively; $\mathrm{p}<0.05)$ and even more strongly with distress from psychotic-like experiences $(\beta=0.107 ; \mathrm{p}<0.001)$ [164].

When cigarette and cannabis smoking were included in the same model, the authors found that cigarette smoking, but not cannabis inhalation, was associated with distress from psychotic symptoms. This suggests that the relationship between cannabis use and distress from psychotic-like experiences is confounded by cigarette smoking [164].

Researchers presented four possible explanations for the association between cigarette smoking and psychotic-like experiences [164]: 
1) Cigarette smoking could increase the risk for psychotic-like experiences through a biological mechanism involving dopamine release and nicotinic cholinergic neurotransmission reported to be related to schizophrenia [172] [173] [174];

2) Nicotine is taken to alleviate psychotic-like symptoms (the self-medication hypothesis) as it improves negative symptoms in psychotic patients and cognitive functions in both healthy individuals and psychotic patients [175]-[180];

3) The correlation between cigarette smoking and psychotic-like experiences could be due to confounding factors such as psychosocial stress [181];

4) Psychotic-like symptoms could result from nicotine withdrawal effects [182].

We should emphasize that the work of Van Gastel et al. could not establish conclusions regarding the direction of causality because it was a cross-sectional study [164]. Therefore, the reverse causation explanation cannot be excluded in this study.

A longitudinal study of 1756 adolescents in the United Kingdom concluded that cigarette smoking and cannabis use at age 16 were both associated, to a similar degree, with psychotic experiences at age 18 (odds ratio $=1.61$; 95\% confidence interval $=1.31-1.98$ for cigarettes; odds ratio $=1.48 ; 95 \%$ confidence interval $=1.18-1.86$ for cannabis). Adjustment for cigarette smoking frequency (odds ratio $=1.27 ; 95 \%$ confidence interval $=0.91-1.76$ ) or other illicit drug use (odds ratio $=1.25 ; 95 \%$ confidence interval $=0.91-1.73$ ) attenuated the relationship between cannabis and psychotic experiences. The attenuation was smaller when cannabis use was adjusted for in the cigarette psychotic experience association (odds ratio $=1.42 ; 95 \%$ confidence interval $=1.05-1.92$ ) [183]

However, almost all the participants used cannabis with tobacco, including those who classed themselves as non-cigarette smokers [183].

It is noteworthy that a meta-analysis concluded that cigarette smoking is not associated with an earlier age of onset of schizophrenia and other psychoses. Therefore, in that study, tobacco consumption was not considered as a confounding factor for the relationship between cannabis use and earlier age of onset of psychosis [184].

\subsection{Urban Environment}

Meta-analyses suggest that people who grew up in an urban environment are consistently associated, in a dose-response manner, with a small increased risk of developing psychosis [146] [185] [186] [187]. This is even more evident if a genetic risk is present [188] [189].

There is growing interest in investigating if urbanicity plays a role in moderating the strength of the cannabis-psychosis relationship [135] [146] [156] [190] [191].

In a 10-year follow up cohort study of 1923 German people, aged 14 - 24 years at baseline, living in the city of Munich or in the rural surroundings, investiga- 
tors found a significant interaction between cannabis and urbanity (adjusted risk difference $=10.9 \% ; 95 \%$ confidence interval $=3.2-18.6 ; \mathrm{p}=0.005$ ). The effect of cannabis use on follow-up incident psychotic symptoms was much stronger in subjects who grew up in an urban environment (adjusted risk difference $=6.8 \%$; $95 \%$ confidence interval $=1.0-12.5 ; \mathrm{p}=0.021$ ) compared with individuals from rural surroundings (adjusted risk difference $=6.8 \%$; $95 \%$ confidence interval $=$ $4.1 \%$; 95\% confidence interval $=-9.8-1.6 ; \mathrm{p}=0.159$ ) [192].

Researchers indicated that those effects were independent from confounding factors such as sex, age, socio-economic status, childhood trauma and use of other drugs. This incidence was not irrelevant, as the majority of subjects exposed to both urbanicity and cannabis developed the psychosis outcome because of their co-action [192]. The findings indicate that the interaction between cannabis use and urbanicity may represent not only an underlying mechanism of moderation (the psychotomimetic effects of cannabis are larger in urban areas) but also of mediation (living in the city may enhance cannabis use). Both mechanisms are important from a public health perspective [192].

After observing that individuals living in the urban environment were more likely to use cannabis at baseline than subjects from the rural area, the authors suggested than an early exposure, i.e. between the ages of 5 and 15 years, to increased social fragmentation associated with an urban environment may constitute an environmental stressor that, through epigenetic mechanisms, induces a progressive behavioral sensitization which leads ultimately to permanent neurodevelopmental alterations. This in turn may contribute to an enhanced sensitivity, later in life, to the psychotomimetic effects of cannabis [192].

\subsection{Protective Role of Cannabidiol against the Cannabis-Psychosis Link}

Beyond the role of dopamine transmission, abnormalities in the brain's endocannabinoid signalling system, resulting in the hyperactivity of this system, are increasingly recognized as etiological factors involved in the development and progression of psychosis [12] [193] [194] [195] [196].

Cannabidiol (CBD), the second most important phytocannabinoid, is the main non-psychoactive constituent of cannabis [197] [198]. Concentrations of cannabidiol (CBD) and $\Delta^{9}$-tetrahydrocannabinol (THC) differ greatly between various types of cannabis products (marijuana, haschisch, oils of marijuana and haschisch), year and place of origin [12]. For instance, in 2008, marijuana produced in the Netherlands contained virtually no cannabidiol and had a mean THC concentration of $16 \%$, whereas haschisch imported from Afghanistan, Morocco or Nepal, contained on average 17\% of THC but also $9 \%$ of cannabidiol [199]. The relative THC/CBD ratio in cannabis varies greatly. Concentrations of CBD can range from almost none to up to $40 \%$ [200]. Higher levels of THC and negligible levels of CBD have been found in cannabis extracts grown hydroponically under intense farming conditions [201]. 
Cannabidiol was first isolated from marijuana in the late 1930s [197]. However, it was not until 1963 that its structure and stereochemistry were elucidated [202].

CBD displays a relatively low affinity for $\mathrm{CB} 1$ and $\mathrm{CB} 2$ receptors but has indirect antagonistic effects on those receptors which could explain its lack of cognitive and other unwanted psychoactive effects characteristic of marijuana and haschisch [195] [197] [203].

In contrast to THC, which is associated with pro-psychotic side effects, CBD possesses no known psychoactive properties [195] [198].

The hypothesis that cannabidiol attenuates the psychotomimetic effects of THC was postulated for the first time in 1982 by Rottanburg et al. who found an increased prevalence of psychotic symptoms among users of cannabis with a high THC concentration and lack of CBD [204]. At the same period, Zuardi et al. observed that the co-administration of $\mathrm{CBD}$ and THC significantly reduced the psychotomimetic symptoms induced by THC [205].

Indeed, several studies have illustrated that the co-administration of CBD and THC may alter the pharmacological actions of the later, potentiating some beneficial effects, while mitigating some of its negative side effects [196] [205] [206] [207].

Other studies have demonstrated the antipsychotic properties of cannabidiol (CBD) and suggested that it can antagonize the negative impact of THC on brain functions [196] [208]-[214] and have protective effects against psychosis [215] [216] [217].

Different preclinical studies have provided evidence of the antipsychotic activity of cannabidiol (CBD), with a pharmacological profile resembling that of haloperidol [197]. Indeed, the effects of CBD were similar to those produced by haloperidol in a rodent model predictive of antipsychotic activity, using different doses of drugs [218]. Interestingly, contrary to haloperidol, CBD was devoid of extrapyramidal side effects, making it a potential candidate to treat different forms of psychosis in humans.

Preliminary clinical case reports also suggested that cannabidiol might exert antipsychotic properties in schizophrenic patients [197] [208] [210] [211].

The analysis of hair samples of 140 cannabis smokers demonstrated that those with low CBD/THC ratios predicted high levels of schizophrenia-like symptoms [212]. Similarly, an association was found between the use of cannabis with high THC and low CBD content and a higher risk of developing a first psychotic episode [219].

In a large cross-sectional sample of 1877 cannabis users from the general population (mean age $=23$ years; $\mathrm{SD}=6.0$ ) who used the same type of cannabis in the majority $(>60 \%)$ of the occasions, researchers found a significant inverse relationship $(\mathrm{F}(1,1877)=14,577 ; \mathrm{p}<0.001)$ between cannabidiol concentration and self-reported positive symptoms, but not with negative symptoms or depression [220]. 
In a British study conducted on 120 current cannabis smokers, 66 daily users and 54 recreational users, investigators performed hair analysis to objectively quantify levels of THC and CBD. Researchers found lower psychosis-like symptoms in subjects whose hair had CBD compared with those without CBD. However, this was observed only in recreational users who had higher levels of THC in their hair [201].

High THC recreational cannabis users with no CBD present in their hair showed much greater levels of psychosis proneness than all other groups. They were also associated with increased depression, anxiety and recall impairments [201].

While analysing their results, researchers indicated that a growing body of evidence suggests that cannabidiol may modulate the psychotomimetic effects of THC not only acutely in laboratory settings giving CBD and THC to healthy volunteers [209] but also chronically in cannabis users [201] [212].

Considering that CBD does not interact directly with the pharmacokinetics of THC, the authors suggested that the mechanism of CBD's modulation of the effects of THC is that CBD chronically counteracts the induction of psychotic-like symptoms by THC [201].

It has been demonstrated that cannabidiol (CBD) modulates powerfully the mesolimbic dopamine system and normalizes both acute and neurodevelopmentally-induced dysregulation of dopaminergic activity states associated with both positive and negative schizophrenia-like psychopathology [195]. This ability of CBD to reverse THC induced hyperactivity of mesolimbic dopaminergic transmission confers to CBD its promising antipsychotic properties [195].

In fact, growing pre-clinical and clinical evidence supports the therapeutic efficacy of cannabidiol (CBD) in a broad range of neuropsychiatric disorders [195] [221]. Indeed, CBD attenuates brain damage caused by ischemic and/or neurodegenerative conditions. It also facilitates neurogenesis by acting on synaptic plasticity. Finally, it has beneficial effects in the treatment of anxiety, depression and psychosis by alleviating some symptoms of these diseases [195] [221] [222] [223] [224]. In terms of toxicity, CBD has few adverse effects, the most frequent side effects reported being sedation and dizziness [198] [225] [226].

In 2012, a pioneering randomized, double-blind, controlled clinical trial of cannabidiol versus amisulpride, a potent antipsychotic medication, demonstrated that CBD has comparable antipsychotic properties in alleviating both positive and negative schizophrenia symptoms and yields to similar significant clinical improvement than amisulpride in the treatment of acute schizophrenia [225].

Moreover, CBD displayed a substantially superior side-effect profile than that of amisulpride. Indeed, compared to amisulpride, treatment with CBD was associated with significantly fewer extrapyramidal symptoms $(p=0.006)$, less weight gain $(\mathrm{p}=0.010)$ and lower prolactin increase, a predictor of galactorrhea and sexual dysfunction $(\mathrm{p}<0.001)$. Furthermore, CBD was well tolerated and did not significantly affect cardiac or hepatic functions [225]. 
Interestingly, the results of Leweke et al. [225] were correlated with increased levels of anandamide, suggesting that inhibition of anandamide deactivation may contribute to the antipsychotic effects of CBD which potentially represents a completely new mechanism of action in the treatment of schizophrenia [198].

In summary, studies conducted with cannabidiol show that cannabis types with a high concentration of cannabidiol (CBD) are significantly less strongly associated with psychotic symptoms. By regulating dopaminergic activities, CBD has the features of a potential efficient antipsychotic medication, while being deprived of the deleterious side effects of the conventional antipsychotic pharmacotherapies. In fact, CBD exerts clinically relevant antipsychotic effects and has a better safety and tolerability profile compared with current antipsychotic medications [225].

\section{Discussion}

Accumulating evidence from longitudinal epidemiologic studies suggests that cannabis use may increase the risk of developing psychosis [23] [24] [25] [26] [27] [29] [32] [47] [58] [69] [86] [227] [228].

A constellation of complex factors may trigger the appearance of psychotic symptoms. This systematic review has identified six risk factors which may contribute to the etiopathogenesis of psychosis or psychotic features:

- Quantity, frequency and duration of cannabis use;

- Early age of cannabis consumption;

- Genetic susceptibility;

- Childhood trauma;

- Cigarette smoking;

- Urban environment.

A dose-response relationship exists between the amounts of cannabis used and the likelihood of developing psychosis or psychotic features: the risk increases with the quantity, frequency and duration of cannabis consumption.

Similarly, early age of cannabis use is correlated with an increased probability of manifesting such symptoms. This observation could be explained by the fact that the brain of young people aged between 14 and 25 years has not reached its complete maturation and therefore is more vulnerable to the psychotomimetic effects of THC and the adverse central manifestations of cannabis [12] [25] [229] [230] [231] [232] [233]. These observations illustrate the critical role played by the endocannabinoid system in the brain maturation, particularly during adolescence.

Regarding genetic susceptibility, it has been demonstrated that psychosis inducing effects of cannabis use are related to genetic variability in the catechol-0methyltransferase (COMT) gene. This vulnerability increases when individuals are exposed to childhood abuse. Cannabis consumption increases the likelihood of developing psychotic experiences (PEs) in Val carriers only when they are exposed to childhood abuse. The risk of manifesting psychotic experiences (PEs) 
depends therefore on the COMT genotypes [93].

Similarly, AKT1 and DRD2 genotypes are involved in the likelihood of developing psychosis [122] [123] [124] [125].

The characterization of potential genes presenting a risk of psychotic outcomes will facilitate the comprehension of the cannabis-psychosis link and will help identify the persons who present a genetic vulnerability to the psychotogenic effects of cannabis.

Child trauma plays also a deleterious role in the expression of psychosis or psychotic features by a progressive sensitization mechanism: exposure to traumatic experiences during childhood may induce neurobiological changes characterized by an over-reactivity of the hypothalamus and the hypothalamic-pituitary adrenal axis, abnormalities in the neurotransmitter system and structural brain changes [152] [234].

Cigarette smoking has also been considered a risk factor for the development of psychosis or psychotic symptoms. It increases the likelihood of manifesting these features in a dose-response manner. A biological mechanism involving dopamine release and nicotinic cholinergic neurotransmission could be involved [172] [173] [174].

Finally, urbanicity increases the strength of the cannabis-psychosis relationship. This phenomenon could be explained by the fact that living in urban areas may enhance cannabis use and render people more vulnerable to the psychotomimetic effects of THC by neurobiological mechanisms [192].

None of each of the six risk factors described is neither necessary, nor sufficient to do so alone [31] [77] [147] [181].

On the other hand, cannabidiol (CBD) plays a protective role in the cannabis-psychosis relationship. Cannabis species with a high concentration of cannabidiol are significantly less strongly associated with psychotic symptoms, rendering $\mathrm{CBD}$ a promising efficient antipsychotic medication. Large randomized-controlled clinical trials will eventually confirm or infirm the qualitative and quantitative antipsychotic potential of cannabidiol (CBD).

However, the causal and temporal association between the use of cannabis and the development of psychosis or psychotic features is not clear and remains controversial [19] [20] [21]. Population statistics argue against the causal relationship. While cannabis use among adolescents has increased substantially in the past 40 years [13], the population trends in schizophrenia incidence have not [14] [228] [235].

Macleod and colleagues have suggested that a non-causal explanation is possible for most of the associations between cannabis use and psychosis: "Cannabis use could be a marker, rather than a cause of a life trajectory more likely to involve adverse outcomes" [14].

Moreover, a large number of studies cannot determine if psychotic features predispose individuals to use cannabis or if cannabis use increases psychotic traits [69]. 
Indeed, several authors have suggested that psychotic experiences at an early age might trigger the use of cannabis as a self-medication [27] [29] [38] [39] [62] [69] [81] [236] [237].

Therefore, the cannabis-psychosis relationship might be bidirectional [27] [29] [39] [54] [81] [90] [238] [239] [240] [241] [242].

A critical consideration should be applied to the interpretation of results and to the strength of the evidence in relation to established criteria for causality. If most authors accept the idea that the association between cannabis and psychosis has not arisen by chance, then, apart from a causal link, three broad explanations should also be taken into consideration [22]:

- Psychosis could predispose to cannabis use (the "reverse causality" explanation);

- Misreporting of cannabis consumption and/or psychotic symptoms could lead to an erroneous association between the two, the link being apparent but spurious (the "reporting bias" explanation);

- Both cannabis use and psychosis could share common antecedents (cofactors) without there being any causal relationship between the two (the "residual confounding" explanation).

Despite the discrepancies and uncertainties in the nature and strength of the cannabis-psychosis relationship, a consensus emerges actually among investigators on the following two points:

1) Cannabis use can precipitate the appearance of psychosis or associated disorders among subjects with a psychotic vulnerability [13] [22] [23] [29] [76].

Indeed, individuals with an established predisposition to psychosis manifest an increased sensitivity to the adverse effects of cannabis and a higher susceptibility to develop the disease [14] [31] [76] [243] [244].

Persistence of cannabis use after a diagnosis or in the presence of psychotic symptoms is consistently correlated with earlier and more frequent relapses, aggravation of some symptoms of the disease and longer and more frequent hospitalizations [22] [50] [51] [58] [141] [143] [245].

2) While there is thus agreement about the role of cannabis as a precipitant factor in persons vulnerable to psychosis, as well as about the effects of cannabis on existing psychosis, the etiological role of cannabis in psychosis should be elucidated, as well as the eventual temporal relationship and pathways involved.

Research strategies aiming at further evaluating the qualitative and quantitative contribution of the six risk factors analysed in this study, as well as alternative criteria, determinants, and explanations will provide clarification to the debate and eventually elucidate the link between cannabis and psychosis.

\section{Conclusions}

This review of the scientific literature found six potential risk factors involved in the association between cannabis and psychosis or psychotic symptoms. They are, in decreasing importance the dose-response relationship (quantity, fre- 
quency and duration of cannabis use), the early age of cannabis consumption, genetic susceptibility, childhood trauma, cigarette smoking and urban environment.

The weight of evidence from existing longitudinal research suggests that those factors are consistently associated with increased rates of both psychosis and psychotic features, even after control for confounding factors and reverse causality. Nonetheless, the cannabis-psychosis link, although replicated convincingly, is rather intriguing quantitatively and appears often weak. If a causal relationship exists, uncertainties arising from a series of methodological issues relating to the assessment of cannabis use, the measurement of psychosis or psychotic features, reverse causality, and the control of residual confounding elements should be ruled out.

To reduce these uncertainties, further research needs to be undertaken with large numbers of volunteers followed over several years. Such an experiment has never been conducted and raises practical and ethical issues.

\section{Conflicts of Interest}

None.

\section{References}

[1] UNODC (2020) World Drug Report 2020. United Nations Office on Drugs and Crime (UNODC), Vienna, $358 \mathrm{p}$.

[2] Ben Amar, M. and Léonard, L. (2002) Chapter 16: Cannabis. In: Léonard, L. and Ben Amar, M., Eds., Les Psychotropes. Pharmacologie et Toxicomanie, Les Presses de l'Université de Montréal, Montréal, 571-627.

[3] Ben Amar, M. (2020) Drogues, Savoir plus, Risquer Moins. Centre québécois de lutte aux dépendances (CQLD), Montréal, 376 p. (In Press)

[4] Devane, W.A., Dysark, F.A., Johnson, M.R., Melvin, L.S. and Howlett, A.C. (1988) Determination and Characterization of a Cannabinoid Receptor in Rat Brain. $\mathrm{Mo}$ lecular Pharmacology, 34, 605-613.

[5] Matsuda, L.A., Lolait, S.J., Brownstein, M.J., Young, A.C. and Bonner, T.I. (1990) Structure of a Cannabinoid Receptor and Functional Expression of the Cloned cDNA. Nature, 346, 561-564. https://doi.org/10.1038/346561a0

[6] Munro, S., Thomas, K.L. and Abu-Shaar, M. (1993) Molecular Characterization of a Peripheral Receptor for Cannabinoids. Nature, 365, 61-65. https://doi.org/10.1038/365061a0

[7] Ben Amar, M. (2006) Cannabinoids in Medicine: A Review of Their Therapeutic Potential. Journal of Ethnopharmacology, 105, 1-25. https://doi.org/10.1016/j.jep.2006.02.001

[8] Hazekamp, A. and Grotenhermen, F. (2010) Review on Clinical Studies with Cannabis and Cannabinoids 2005-2009. Cannabinoids, 5, 1-21. https://doi.org/10.1159/000489141

[9] Whiting, P.F., Wolff, R.F., Deshpande, S., Diniscio, M., Duffy, S. and Hernandez, A.V. (2015) Cannabinoids for Medical Use: A Systematic Review and Meta-Analysis. Journal of the American Medical Association, 313, 2456-2476. https://doi.org/10.1001/jama.2015.6358 
[10] Kowal, M.A., Hazekamp, A. and Grotenhermen, F. (2016) Review on Clinical Studies with Cannabis and Cannabinoids 2010-2014. Cannabinoids, 11, 1-18.

[11] National Academies of Sciences, Engineering, and Medicine (2017) Chapter 4: Therapeutic Effects of Cannabis and Cannabionoids. In: The Health Effects of Cannabis and Cannabinoids. The Current State of Evidence and Recommendations for Research, The National Academies Press, Washington DC, 4-1-4-43.

[12] Ben Amar, M. (2018) Le cannabis: Pharmacologie et toxicologie. Centre québécois de lutte aux dépendances (CQLD), Montréal, $511 \mathrm{p}$.

[13] Degenhardt, L., Hall, W. and Linskey, M. (2003) Testing Hypotheses about the Relationship between Cannabis Use and Psychosis. Drug and Alcohol Dependence, 71, 37-48. https://doi.org/10.1016/S0376-8716(03)00064-4

[14] Macleod, J., Oakes, R., Copello, A., Crome, I., Egger, M., Hickman, M., Oppenkowski, T., Stokes-Lampard, H. and Davey Smith, G. (2004) Psychological and Social Sequelae of Cannabis and Other Illicit Drug Use by Young People: A Systematic Review of Longitudinal, General Population Studies. The Lancet, 363, 1579-1588. https://doi.org/10.1016/S0140-6736(04)16200-4

[15] McGrath, J.J. (2006) Variations in the Incidence of Schizophrenia: Data versus Dogma. Schizophrenia Bulletin, 32, 195-197. https://doi.org/10.1093/schbul/sbi052

[16] Hickman, M., Vickerman, P., Macleod, J., Kirkbride, J. and Jones, P.B. (2007) Cannabis and Schizophrenia: Model Projections on the Impact of the Rise in Cannabis Use on Historical and Future Trends in Schizophrenia in England and Wales. $A d$ diction, 102, 597-606. https://doi.org/10.1111/j.1360-0443.2006.01710.x

[17] Potvin, S. and Ben Amar, M. (2008) Review: Cannabis Use Increases the Risk of Psychotic Outcomes. Evidence Based Mental Health, 11, 28. https://doi.org/10.1136/ebmh.11.1.28

[18] Fergusson, D.M., Poulton, R., Smith, P.F. and Boden, J.M. (2006) Cannabis and Psychosis. British Medical Journal, 332, 172-175.

https://doi.org/10.1136/bmj.332.7534.172

[19] Gage, S.H., Zammit, S. and Hickman, M. (2013) Stronger Evidence Is Needed before Accepting That Cannabis Plays an Important Role in the Aetiology of Schizophrenia in the Population. F1000 Medicine Reports, 5, 1-5. https://doi.org/10.3410/M5-2

[20] Proal, A.C., Fleming, J., Galvez-Buccollini, J.A. and De Lisi, L.E. (2014) A Controlled Family Study of Cannabis Users with and without Psychosis. Schizophrenia Research, 152, 283-288. https://doi.org/10.1016/j.schres.2013.11.014

[21] Ksir, C. and Hart, C.L. (2016) Cannabis and Psychosis: A Critical Overview of the Relationship. Current Psychiatry Reports, 18, 12. https://doi.org/10.1007/s11920-015-0657-y

[22] Ben Amar, M. and Potvin, S. (2007) Cannabis and Psychosis: What Is the Link? Journal of Psychoactive Drugs, 39, 131-142. https://doi.org/10.1080/02791072.2007.10399871

[23] Van Os, J., Bak, M., Hanssen, M., Bijl, R.V., De Graaf, R. and Verdoux, H. (2002) Cannabis Use and Psychosis: A Longitudinal Population-Based Study. American Journal of Epidemiology, 156, 319-327. https://doi.org/10.1093/aje/kwf043

[24] Zammit, S., Allebeck, P., Andreasson, S., Lundberg, J. and Lewis, G. (2002) Self-Reported Cannabis Use as a Risk Factor for Schizophrenia in Swedish Conscripts of 1969: Historical Cohort Study. British Medical Journal, 325, 1199-1201. https://doi.org/10.1136/bmj.325.7374.1199

[25] Arseneault, L., Cannon, M., Poulton, R., Murray, R., Caspi, A. and Moffitt, T.E. 
(2002) Cannabis Use in Adolescence and Risk for Adult Psychosis: Longitudinal Prospective Study. British Medical Journal, 325, 1212-1213. https://doi.org/10.1136/bmj.325.7374.1212

[26] Fergusson, D.M., Harword, L.J. and Swain-Campbell, N.R. (2003) Cannabis Dependence and Psychotic Symptoms in Young People. Psychological Medicine, 33, 15-21. https://doi.org/10.1017/S0033291702006402

[27] Ferdinand, R.F., Sondeijker, F., Van Der Ende, J., Selten, J.P., Huizink, A. and Verhulst, F.C. (2005) Cannabis Use Predicts Future Psychotic Symptoms, and Vice Versa. Addiction, 100, 612-618. https://doi.org/10.1111/j.1360-0443.2005.01070.x

[28] Fergusson, D.M., Harwood, L.J. and Ridder, E.M. (2005) Tests of Causal Linkages between Cannabis Use and Psychotic Symptoms. Addiction, 100, 354-366.

https://doi.org/10.1111/j.1360-0443.2005.01001.x

[29] Henquet, C., Krabbendam, L., Spauwen, J., Kaplan, C., Lieb, R., Wittchen, H.U. and Van Os, J. (2005) Prospective Cohort Study Cannabis Use, Predisposition for Psychosis, and Psychotic Symptoms in Young People. British Medical Journal, 330, 11. https://doi.org/10.1136/bmj.38267.664086.63

[30] Phillips, L.J., Curry, C., Yung, A.R., Yuen, H.P., Adlard, S. and McGorry, P.D. (2002) Cannabis Use Is Not Associated with the Development of Psychosis in an "Ultra High Risk" Group. Australian and New Zealand Journal of Psychiatry, 36, 800-806. https://doi.org/10.1046/j.1440-1614.2002.01089.x

[31] Arseneault, L., Cannon, M., Witton, J. and Murray, R.M. (2004) Causal Association between Cannabis and Psychosis: Examination of the Evidence. British Journal of Psychiatry, 184, 110-117. https://doi.org/10.1192/bjp.184.2.110

[32] Henquet, C., Murray, R., Linszen, D. and Van Os, J. (2005) The Environment and Schizophrenia: The Role of Cannabis Use. Schizophrenia Bulletin, 31, 608-612. https://doi.org/10.1093/schbul/sbi027

[33] Monshouwer, K., Van Drosselaer, S., Verdurmen, J., Bogt, T.T., De Graaf, R. and Vollebergh, W. (2006) Cannabis Use and Mental Health in Secondary School Children. Findings from a Dutch Survey. British Journal of Psychiatry, 188, 148-153. https://doi.org/10.1192/bjp.188.2.148

[34] Moore, T.H.M., Zammit, S., Lingford-Hughes, A., Barnes, T.R.E, Jones, P.B., Burke, M. and Lewis, G. (2007) Cannabis Use and Risk of Psychotic or Affective Mental Health Outcomes: A Systematic Review. The Lancet, 370, 319-328. https://doi.org/10.1016/S0140-6736(07)61162-3

[35] González-Pinto, A., Vega, P., Ibañez, B., Mosquera, F., Barbeito, S., Gutiérrez, M., Ruiz, I. and Viera, E. (2008) Impact of Cannabis and Other Drugs on Age at Onset of Psychosis. The Journal of Clinical Psychiatry, 69, 1210-1216. https://doi.org/10.4088/JCP.v69n0802

[36] Miettunen, J., Törmänen, S., Murray, G.K., Jones, P.B., Mäki, P., Ebeling, H., Moilanen, I., Taanila, A., Heinimaa, M., Joukamaa, M. and Veijola, J. (2008) Association of Cannabis Use with Prodromal Symptoms of Psychosis in Adolescence. The British Journal of Psychiatry, 192, 470-471. https://doi.org/10.1192/bjp.bp.107.045740

[37] Bailly, D. (2009) Adolescence et schizophrénie. L'encéphale, No. 1, S10-S19. https://doi.org/10.1016/S0013-7006(09)75527-7

[38] McGrath, J., Welham, J., Scott, J., Varghese, D., Degenhardt, L., Hayatbakhsh, M.R., Alati, R., Williams, G.M., Bor, W. and Najman, J.M. (2010) Association between Cannabis Use and Psychosis-Related Outcomes Using Sibling Pair Analysis in a Cohort of Young Adults. Archives of General Psychiatry, 67, 440-447. https://doi.org/10.1001/archgenpsychiatry.2010.6 
[39] Kuepper, R., Van Os, J., Lieb, R., Wittchen, H.U., Hofler, M. and Henquet, C. (2011) Continued Cannabis Use and Risk of Incidence and Persistence of Psychotic Symptoms: 10 Year Follow-Up Cohort Study. British Medical Journal, 342, d738. https://doi.org/10.1136/bmj.d738

[40] Van der Steur, S.J., Batalla, A. and Bossong, M.G. (2020) Factors Moderating the Association between Cannabis Uses and Psychosis Risk: A Systematic Review. Brain Sciences, 10, 97. https://doi.org/10.3390/brainsci10020097

[41] Manrique-Garcia, E., Zammit, S., Dalman, C., Hemmingsson, T., Andreasson, S. and Allebeck, P. (2012) Cannabis, Schizophrenia and Other Non-Affective Psychoses: 35 Years of Follow-Up of a Population-Based Cohort. Psychological Medicine, 42, 1321-1328. https://doi.org/10.1017/S0033291711002078

[42] Ruiz-Veguilla, M., Barrigón, M.L., Hernández, L., Rubio, J.L., Gurpegui, M., Sarramea, F., Cervilla, J., Gutiérrez, B., James, A. and Ferrin, M. (2013) Dose-Response in a Non-Clinical Population: Evidence from a Snowball Sample. Journal of Psychiatric Research, 47, 1036-1043. https://doi.org/10.1016/j.jpsychires.2013.03.003

[43] Di Forti, M., Sallis, H., Allegri, F., Trotta, A., Ferraro, L., Stilo, S.A., Marconi, A., La Cascia, C., Reis Marques, T., Pariante, C., Dazan, P., Mondelli, V., Paparelli, A., Kolliakou, A, Prata, D., Gaughran, F., David, A.S., Morgan, C., Stahl, D., Khondoker, M., MacCabe, J.H. and Murray, R.M. (2014) Daily Use, Especially of High-Potency Cannabis, Drives the Earlier Onset of Psychosis in Cannabis Users. Schizophrenia Bulletin, 40, 1509-1517. https://doi.org/10.1093/schbul/sbt181

[44] Valmaggia, L., Day, F., Jones, C., Bissoli, S., Pugh, C., Hall, D., Bhattacharyya, S., Howes, O., Stone, J. and Fusar-Poli, P. (2014) Cannabis Use and Transition to Psychosis in People at Ultra-High Risk. Psychological Medicine, 44, 2503-2512. https://doi.org/10.1017/S0033291714000117

[45] Barrigón, M.L., Diaz, F.J., Gurpegui, M., Ferrin, M., Salcedo, M.D., Moreno-Granados, J., Cervilla, J.A. and Ruiz-Veguilla, M. (2015) Childhood Trauma as a Risk Factor for Psychosis: A Sib-Pair Study. Journal of Psychiatric Research, 70, 130-136. https://doi.org/10.1016/j.jpsychires.2015.08.017

[46] Andrade, C. (2016) Cannabis and Neuropsychiatry: The Longitudinal Risk of Psychosis as an Adverse Outcome. Journal of Clinical Psychiatry, 77, 739-742. https://doi.org/10.4088/JCP.16f10918

[47] Gage, S.H., Hickman, M. and Zammit, S. (2016) Association between Cannabis and Psychosis: Epidemiologic Evidence. Biological Psychiatry, 79, 549-556.

https://doi.org/10.1016/j.biopsych.2015.08.001

[48] Marconi, A., Di Forti, M., Lewis, C.M., Murray, R.M. and Vassos, E. (2016) Meta-Analysis of the Association between the Level of Cannabis Use and Risk of Psychosis. Schizophrenia Bulletin, 42, 1262-1269.

https://doi.org/10.1093/schbul/sbw003

[49] Murray, R.M., Quigley, H., Quattrone, D., Englund, A. and Di Forti, M. (2016) Traditional Marijuana, High-Potency Cannabis and Synthetic Cannabinoids: Increasing Risk for Psychosis. World Psychiatry, 15, 195-204. https://doi.org/10.1002/wps.20341

[50] Hamilton, I. (2017) Cannabis, Psychosis and Schizophrenia: Unravelling a Complex Interaction. Addiction, 112, 1653-1657. https://doi.org/10.1111/add.13826

[51] Large, M. and Nielssen, O. (2017) Daily Use of High-Potency Cannabis Is Associated with an Increased Risk of Admission and More Intervention after First-Episode Psychosis. Evidence Based Mental Health, 20, 58. https://doi.org/10.1136/eb-2017-102630 
[52] Mallet, J., Ramoz, N., Le Strat, Y., Gorwood, P. and Dubertret, C. (2017) Heavy Cannabis Use Prior Psychosis in Schizophrenia: Clinical, Cognitive and Neurological Evidences for a New Endophenotype? European Archives of Psychiatry and Clinical Neuroscience, 267, 629-638. https://doi.org/10.1007/s00406-017-0767-0

[53] McHugh, M.S., McGorry, P.D., Yung, A.R., Lin, A., Wood, S.J., Hartman, J.A. and Nelson, B. (2017) Cannabis-Induced Attenuated Psychotic Symptoms: Implications for Prognosis in Young People at Ultra-High Risk for Psychosis. Psychological Medicine, 47, 616-626. https://doi.org/10.1017/S0033291716002671

[54] Degenhardt, L., Saha, S., Lim, C.C.W., Aguilar-Gaxiola, S., Al-Hamzawi, A., Alonso, J., Andrade, L.H., Bromet, E.J., Bruffaerts, R., Caldas-de-Almeida, J.M., de Girolamo, G., Florescu, S., Gurege, O., Haro, J.M., Karam, E.G., Karam, G., Kovess-Masfety, V., Lee, S., Lépine, J.P., Makanjuola, V., Medina-Mora, M.E., Mneimneh, Z., Navarro-Mateu, F., Piazza, M., Posada-Villa, J., Sampson, N.A., Scott, K.M., Stagnaro, J.C., TenHave, M., Kendler, K.S., Kessler, R.C., McGrath, J.J. and on Behalf of the WHO World Mental Health Survey Collaborators (2018) The Associations between Psychotic Experiences and Substance Use Disorders: Findings from the World Health Organization World Mental Health Surveys. Addiction, 113, 924-934. https://doi.org/10.1111/add.14145

[55] Ortiz-Medina, M.B., Perea, M., Torales, J., Ventriglio, A., Vitrani, G., Aguilar, L. and Roncero, C. (2018) Cannabis Consumption and Psychosis or Schizophrenia Development. International Journal of Social Psychiatry, 64, 690-704. https://doi.org/10.1177/0020764018801690

[56] Di Forti, M., Quattrone, D., Freeman, T.P., Tripoli, G., Gayer-Anderson, C., Quigley, H., Rodriguez, V., Jongsma, H.E., Ferraro, L., La Cascia, C., La Barbera, D., Tarricone, I., Berardi, D., Szöke, A., Arango, C., Torkelli, A., Velthorst, E., Bernardo, M., Del-Ben, C.M., Rossi Menezes, P., Selten, J.P., Jones, P.B., Kirkbride, J.B., Rutten, B.P.F., de Haan, L., Sham, P.C., Van Os, J., Lewis, C.M., Lynskey, M., Morgan, C., Murray, R.M. and the EU-GEI WP2 Group (2019) The Contribution of Cannabis Use to Variation in the Incidence of Psychotic Disorder across Europe (EU-GEI): A Multicentre Case-Central Study. The Lancet Psychiatry, 6, 427-436. https://doi.org/10.1016/S2215-0366(19)30048-3

[57] Fekih-Romdhane, F., Hakiri, A., Fadhel, S.B. and Cheour, M. (2019) Cannabis Use in Subjects at Ultra High Risk for Psychosis. Presse Médicale, 48, 1229-1236. https://doi.org/10.1016/j.lpm.2019.09.030

[58] Hasan, A., Von Keller, R., Friemel, C.M., Hall, W., Schneider, M., Koethe, D., Leweke, F.M., Strube, W. and Hoch, E. (2019) Cannabis Use and Psychosis: A Review of Reviews. European Archives of Psychiatry and Clinical Neuroscience, 270, 403-412.

[59] Sideli, L., Quigley, H., La Cascia, C. and Murray, R.M. (2019) Cannabis Use and the Risk of Psychosis and Affective Disorders. Journal of Dual Diagnosis, 16, 22-42. https://doi.org/10.1080/15504263.2019.1674991

[60] Casadio, P., Fernandes, C., Murray, R.M. and Di Forti, M. (2011) Cannabis Use in Young People: The Risk for Schizophrenia. Neuroscience and Biobehavioral Review, 35, 1779-1787. https://doi.org/10.1016/j.neubiorev.2011.04.007

[61] Burns, J.K. (2013) Pathways from Cannabis to Psychosis: A Review of the Evidence. Frontiers in Psychiatry, 4, 64-80. https://doi.org/10.3389/fpsyt.2013.00128

[62] Kraan, T., Velhrorst, E., Koenders, L., Zwaart, K., Ising, H.K., Van Den Berg, D., De Haan, L. and Van der Gaag, M. (2016) Cannabis Use and Transition to Psychosis in Individuals at Ultra-High Risk: Review and Meta-Analysis. Psychological Medicine, 46, 673-681. https://doi.org/10.1017/S0033291715002329 
[63] Di Forti, M., Marconi, A., Carra, E., Fraietta, S., Trotta, A., Bonomo, M., Bianconi, F., Gardner-Sood, P., O’Connor, J., Russo, M., Stilo, S.A., Marques, T.R., Mandelli, V., Dazzan, P., Pariante, C., David, A.S., Gaughran, F., Atakan, Z., Lyegbe, C., Powell, J., Morgan, C., Lynskey M. and Murray, R.M. (2015) Proportion of Patients in South London with First-Episode Psychosis Attributable to Use of High Potency Cannabis: A Case Control Study. The Lancet Psychiatry, 2, 233-238. https://doi.org/10.1016/S2215-0366(14)00117-5

[64] Verdoux, H., Gindre, C., Sorbara, F., Tourmier, M. and Swendsen, J.D. (2003) Effects of Cannabis and Psychosis Vulnerability in Daily Life: An Experience Sampling Test Study. Psychological Medicine, 33, 23-32.

https://doi.org/10.1017/S0033291702006384

[65] Stefanis, N.C., Delespaul, P., Henquet, C., Bakoula, C., Stefanis, C.N. and Van Os, J. (2004) Early Adolescent Cannabis Exposure and Positive and Negative Dimensions of Psychosis. Addiction, 99, 1333-1341. https://doi.org/10.1111/j.1360-0443.2004.00806.x

[66] Hides, L., Lubman, D.I., Buckby, J., Yuen, H.P., Cosgrave, E., Baker, K. and Yung, A.R. (2009) The Association between Early Cannabis Use and Psychotic-Like Experiences in a Community Adolescent Sample. Schizophrenia Research, 112, 130-135. https://doi.org/10.1016/j.schres.2009.04.001

[67] Skinner, R., Conlon, L., Gibbons, D. and McDonald, C. (2011) Cannabis Use and Non-Clinical Dimensions of Psychosis in University Students Presenting to Primary Care. Acta Psychiatrica Scandinavica, 123, 21-27. https://doi.org/10.1111/j.1600-0447.2010.01546.x

[68] Van Gastel, W.A. Wigman, J.T.W., Monshouwer, K., Kahn, R.S., Van Os, J., Boks, M.P.M. and Vollebergh, W.A.M. (2011) Cannabis Use and Subclinical Positive Psychotic Experiences in Early Adolescence: Findings from a Dutch Survey. Addiction, 107, 381-387. https://doi.org/10.1111/j.1360-0443.2011.03626.x

[69] Davis, G.P., Compton, M.T., Wang, S., Levin, F.R. and Blanco, C. (2013) Association between Cannabis Use, Psychosis, and Schizotypal Personality Disorder: Findings from the National Epidemiology Survey on Alcohol and Related Conditions. Schizophrenia Research, 151, 197-202. https://doi.org/10.1016/j.schres.2013.10.018

[70] Lataster, T., Van Os, J., Drukker, M., Henquet, C., Feron, F., Gunther, N. and Myin-Germeys, I. (2006) Childhood Victimisation and Developmental Expression of Non-Clinical Delusional Ideation and Hallucinatory Experiences: Victimisation and Non-Clinical Psychotic Experiences. Social Psychiatry and Psychiatric Epidemiology, 41, 423-428. https://doi.org/10.1007/s00127-006-0060-4

[71] Campbell, M.L.C. and Morrison, A.P. (2007) The Relationship between Bullying, Psychotic like Experiences and Appraisals in 14-16 Year Olds. Behaviour Research and Therapy, 45, 1579-1591. https://doi.org/10.1016/j.brat.2006.11.009

[72] Schreier, A., Wolke, D., Thomas, K., Horwood, J., Hollis, C., Gunnell, D., Lewis, G., Thompson, A., Zammit, S., Duffy, L., Salvi, G. and Harrison, G. (2009) Prospective Study of Peer Victimization in Childhood and Psychotic Symptoms in a Nonclinical Population at Age 12 Years. Archives of General Psychiatry, 66, 527-536. https://doi.org/10.1001/archgenpsychiatry.2009.23

[73] Barrigón, M.L., Gurpegui, M., Ruiz-Veguilla, M., Diaz, F.J., Anguita, M., Sarramea, F. and Cervilla, J., (2010) Temporal Relationship of First-Episode Non-Affective Psychosis with Cannabis Use: A Clinical Verification of an Epidemiological Hypothesis. Journal of Psychiatric Research, 44, 413-420.

https://doi.org/10.1016/j.jpsychires.2009.10.004 
[74] Schubart, C.D., Van Gastel, W.A., Breetvelt, E.J., Beetz, S.L., Ophoff, R.A., Sommer, I.E., Kahn, R.S. and Boks, M.P. (2011) Cannabis Use at a Young Age Is Associated with Psychotic Experiences. Psychological Medicine, 41, 1301-1310. https://doi.org/10.1017/S003329171000187X

[75] Arseneault, L., Cannon, M., Fisher, H.L., Polancyk, G., Moffitt, T.E. and Caspi, A. (2011) Childhood Trauma and Children's Emerging Psychotic Symptoms: A Genetically Sensitive Longitudinal Cohort Study. American Journal of Psychiatry, 168, 65-72. https://doi.org/10.1176/appi.ajp.2010.10040567

[76] Large, M., Sharma, S., Compton, M.T., Slade, T. and Nielssen, O. (2011) Cannabis Use and Earlier Onset of Psychosis: A Systematic Meta-Analysis. Archives of General Psychiatry, 68, 555-561. https://doi.org/10.1001/archgenpsychiatry.2011.5

[77] D’Souza, D.C., Radbakrishnan, R., Sherif, M., Cortes-Brimes, J., Cahill, J., Gupta, S., Skosnik, P.D. and Ranganathan, M. (2016) Cannabinoids and Psychosis. Current Pharmaceutical Design, 22, 6380-6391. https://doi.org/10.2174/1381612822666160826105628

[78] Mané, A., Bergé, D., Penzol, M.J., Parellada, M., Bioque, M., Lobo, A., Gonzalez-Pinto, A., Corripio, I., Cabrena, B., Sánchez-Torres, A.M., Saiz-Ruiz, J., Bernardo, M. and Group, P. (2017) Cannabis Use, COMT, BDNF and Age at First-Episode Psychosis. Psychiatry Research, 250, 38-43.

https://doi.org/10.1016/j.psychres.2017.01.045

[79] Hosseini, S. and Oremus, M. (2019) The Effect of Age of Initiation of Cannabis Use on Psychosis, Depression, and Anxiety among Youth under 25 Years. Canadian Journal of Psychiatry, 64, 304-312. https://doi.org/10.1177/0706743718809339

[80] Konings, M., Henquet, C., Maharajh, H.D., Hutchinson, G. and Van Os, J. (2008) Early Exposure to Cannabis and Risk for Psychosis in Young Adolescents in Trinidad. Acta Psychiatrica Scandinavica, 118, 209-213. https://doi.org/10.1111/j.1600-0447.2008.01202.x

[81] Mackie, C.J., O’Leary-Barrett, M., Al-Khudhairy, N., Castellanos-Ryan, N., Struve, M., Topper, L. and Conrod, P. (2013) Adolescent-Bullying, Cannabis Use and Emerging Psychotic Experiences: A Longitudinal General Population Study. Psychological Medicine, 43, 1033-1044. https://doi.org/10.1017/S003329171200205X

[82] Griffith-Lendering, M.F.H., Wigman, J.T.W., Van Leeuwen, A.P., Huijbregts, S.C.J., Huizink, A.C., Ormel, J., Verhust, F.C., Van Os, J., Swaab, H. and Vollebergh, W.A.M. (2012) Cannabis Use and Vulnerability for Psychosis in Early Adolescence-A Trails Study. Addiction, 108, 733-740. https://doi.org/10.1111/add.12050

[83] Dragt, S., Nieman, D.H., Schultze-Lutter, F., Van Der Meer, F., Becker, H., De Haan, L., Dingemans, P.M., Birchwood, M., Patterson, R., Salokangas, R.K., Heinimaa, M., Heinz, A., Juckel, G., Graf Von Reventlow, H., French, P., Stevens, H., Ruhrmann, S., Klosterkötter, J., Linszen, D.H. and on Behalf of the EPOS Group (2012) Cannabis Use and Age at Onset of Symptoms in Subjects at Clinical High Risk for Psychosis. Acta Psychiatrica Scandinavica, 125, 45-53. https://doi.org/10.1111/j.1600-0447.2011.01763.x

[84] Spauwen, J., Krabbendam, I., Lieb, R., Wittchen, H.U. and Van Os, J. (2006) Impact of Psychological Trauma on the Development of Psychotic Symptoms: Relationship with Psychosis Proneness. British Journal of Psychiatry, 188, 527-533.

https://doi.org/10.1192/bjp.bp.105.011346

[85] Bossong, M.G. and Niesink, R.J. (2010) Adolescent Brain Maturation, the Endogenous Canabinoid System and the Neurobiology of Cannabis-Induced Schizophrenia. Progress in Neurobiology, 92, 370-385. 
https://doi.org/10.1016/j.pneurobio.2010.06.010

[86] Andreasson, S., Allebeck, P., Engström, A. and Rydberg, U. (1987) Cannabis and Schizophrenia. A Longitudinal Study of Swedish Conscripts. The Lancet, 2, 1483-1485. https://doi.org/10.1016/S0140-6736(87)92620-1

[87] Weiser, M., Reichenberg, A., Gratto, I., Yavitzsky, R., Mark, M., Knobler, H.Y., Nahon, D. and Davidson, M. (2003) Self-Reported Drug Abuse Schizophrenia. Biological Psychiatry, 54, 655-660. https://doi.org/10.1016/S0006-3223(03)00110-0

[88] Leroy, S., Griffon, N., Bourdel, M.C., Olié, J.P., Poirier, M.F. and Krebs, M.O. (2001) Schizophrenia and the Cannabinoid Receptor Type 1 (CB1): Association Study Using a Single-Base Polymorphism in Coding Exon 1. American Journal of Medical Genetics (Neuropsychiatric Genetics), 105, 749-752.

https://doi.org/10.1002/ajmg.10038

[89] Ujike, H., Takaki, M., Nakata, K., Tanaka, Y., Takeda, T., Kodama, M., Fujiwara, Y., Sakai, A. and Kuroda, S. (2002) CNR1, Central Cannabinoid Receptor Gene, Associated with Susceptibility to Hebephrenic Schizophrenia. Molecular Psychiatry, 7, 515-518. https://doi.org/10.1038/sj.mp.4001029

[90] Nesvág, R., Reichborn-Kjennerud, T., Gillespie, N.A., Knudsen, G.P., Bramness, J.G., Kendler, K.S. and Ystrom, E. (2017) Genetic and Environmental Contributions to the Association between Cannabis Use and Psychotic-Like Experiences in Young Adult Twins. Schizophrenia Bulletin, 43, 644-653. https://doi.org/10.1093/schbul/sbw101

[91] Karcher, N.R., Barch, D.M., Demers, C.H., Baranger, D.A.A., Health, A.C., Lynskey, M.T. and Agrawal, A. (2019) Genetic Predisposition vs Individual-Specific Processes in the Association between Psychotic-Like Experiences and Cannabis Use. JAMA Psychiatry, 76, 87-94. https://doi.org/10.1001/jamapsychiatry.2018.2546

[92] Kirli, U., Binbay, T., Drukker, M., Elbi, H., Kayahan, B., Gökçelli, D.K., Özkinay, F., Ohay, H., Alptekin, K. and Van Os, J. (2019) Is BDNF-Val 66 Met Polymorphism Associated with Psychotic Experiences and Psychotic Disorder Outcome? Evidence from a 6 Years Prospective Population-Based Cohort Study. American Journal of Medical Genetics, 1808, 113-121. https://doi.org/10.1002/ajmg.b.32641

[93] Alemany, S., Arias, B., Fatjó-Vilas, M., Villa, H., Moya, J., Ibañez, M.I., Ortet, G., Gastó, C. and Fañanas, L. (2014) Psychosis-Inducing Effects of Cannabis Are Related to Both Childhood Abuse and COMT Genotypes. Acta Psychiatrica Scandinavica, 129, 54-62. https://doi.org/10.1111/acps.12108

[94] Chen, J., Lipska, B.K., Halim, N., Ma, Q.D., Matsumoto, M., Melhem, S., Kolachana, B.S., Hyde, T.M., Herman, M.M., Apud, S., Egan, M.F., Kleinman, J.E. and Weinberger, D.R. (2004) Functional Analysis of Genetic Variation in Catechol-O-Methyltransferase (COMT): Effects on MRNA, Protein and Enzyme Activity in Postmortem Human Brain. American Journal of Human Genetics, 75, 807-821. https://doi.org/10.1086/425589

[95] Tunbridge, E.M., Dunn, G., Murray, R.M., Evans, N., Lester, R., Stumpenhorst, K., Harrison, P.J., Morrison, P.D. and Freeman, D. (2015) Genetic Moderation of the Effects of Cannabis: Catechol-O-Methyltransferase (COMT) Affects the Impact of 49-Tetrahydrocannabinol (THC) on Working Memory Performance But Not on the Occurrence of Psychotic Experiences. Journal of Psychopharmacology, 29, 1146-1151. https://doi.org/10.1177/0269881115609073

[96] Meyer-Lindenberg, A., Kohn, P.D., Kolachana, B., Kippenhan, S., McInerney-Leo, A., Nussbaum, R., Weinberger, D.R. and Berman, K.F. (2005) Midbrain Dopamine and Prefontal Function in Humans: Interaction and Modulation by COMT Geno- 
type. Nature Neuroscience, 8, 594-596. https://doi.org/10.1038/nn1438

[97] Nieman, D.H., Dragt, S., Van Duin, E.D.A., Denneman, N., Overbeek, J.M., De Haan, L., Rietdijk, J., Ising, H.K., Klaassen, R.M.C., Van Amelsvoort, T., Wunderink, L., Van Der Gaag, M. and Linszen, D.H. (2016) COMT Val ${ }^{158}$ Met Genotype and Cannabis Use in People with an at Risk Mental State for Psychosis: Exploring Gene x Environment Interactions. Schizophrenia Research, 174, 24-28.

https://doi.org/10.1016/j.schres.2016.03.015

[98] Mannisto, P.T. and Kaakkola, S. (1999) Catechol-O-Methyltransferase (COMT): Biochemistry, Molecular Biology, Pharmacology, and Clinical Efficacy of the New Selective COMT Inhibitors. Pharmacological Reviews, 51, 593-628.

[99] Kapur, S. (2003) Psychosis as a State of Aberrant Salience: A Framework Linking Biology, Phenomenology and Pharmacology in Schizophrenia. American Journal of Psychiatry, 160, 13-23. https://doi.org/10.1176/appi.ajp.160.1.13

[100] Howes, O.D., Montgomery, A.J., Asselin, M.C., Murray, R.M., Valli, I., Tabraham, P., Bramon-Bosch, E., Valmaggia, L., Johns, I., Broome, M., McGuire, P.K. and Grasby, P.M. (2009) Elevated Striatal Dopamine Function Linked to Promodal Signs of Schizophrenia. Archives of General Psychiatry, 66, 13-20.

https://doi.org/10.1001/archgenpsychiatry.2008.514

[101] Kuepper, R., Morrison, P.D., Van Os, J., Murray, R.M., Kenis, G. and Henquet, C. (2010) Does Dopamine Mediate the Psychosis-Inducing Effects of Cannabis? A Review and Integration of Findings across Disciplines. Schizophrenia Research, 121, 107-117. https://doi.org/10.1016/j.schres.2010.05.031

[102] Pelayo-Teran, J.M., Suarez-Pinilla, P., Chadi, N. and Crespo-Facorro, B. (2012) Gene Environment Interactions Underlying the Effect of Cannabis in First Episode Psychosis. Current Pharmaceutical Design, 18, 5024-5035.

https://doi.org/10.2174/138161212802884609

[103] Van Winkel, R., Henquet, C., Rosa, A., Papiol, S., Fananás, L., De Hert, M., Peuskens, I., Van Os, J. and Myin-Gerneys, I. (2008) Evidence That the COMT (Val 158 Met) Polymorphism Moderates Sensitivity to Stress in Psychosis: An Experience Sampling Study. American Journal of Medical Genetics Neuropsychiatric Genetics, 147B, 10-17. https://doi.org/10.1002/ajmg.b.30559

[104] Collip, D., Van Winkel, R., Peerbooms, O., Lataster, T., Thewissen, V., Lardinois, M., Drukker, M., Rutten, B.P.F., Van Os, J. and Myin-Germeys, I. (2011) COMT Val ${ }^{158}$ Met-Stress Interaction in Psychosis: Role of Background Psychosis Risk. CNS Neuroscience and Therapeutics, 17, 612-619. https://doi.org/10.1111/j.1755-5949.2010.00213.x

[105] Peerbooms, O., Rutten, B.P.F., Collip, D., Lardinois, M., Lataster, T., Thewissen, V., Rad, S.M., Drukker, M., Kenis, G., Van Os, I., Myin-Germeys, I. and Van Winkel, R. (2012) Evidence That Interactive Effects of COMT and MTHFR Moderate Psychotic Response to Environmental Stress. Acta Psychiatrica Scandinavica, 125, 247-256. https://doi.org/10.1111/j.1600-0447.2011.01806.x

[106] Caspi, A., Moffitt, T.E., Cannon, M., McClay, J., Murray, R., Harrington, H., Taylor, A., Arseneault, L. Williams, B., Brathwaite, A., Poulton, R. and Craig, I.W. (2005) Moderation of the Effect of Adolescent-Onset Cannabis Use on Adult Psychosis by a Functional Polymorphism in the Catechol-O-Methyltransferase Gene: Longitudinal Evidence of a Gene X Environment Interaction. Biological Psychiatry, 57, 1117-1127. https://doi.org/10.1016/j.biopsych.2005.01.026

[107] Zammit, S., Spurlock, G., Williams, H., Norton, N., Williams, N., O’Donovan, M.C. and Owen, M.J. (2007) Genotype Effects of CHRNA7, CNR1 and COMT in Schi- 
zophrenia: Interactions with Tobacco and Cannabis Use. British Journal of Psychiatry, 191, 402-407. https://doi.org/10.1192/bjp.bp.107.036129

[108] Zammit, S., Owen, M.J., Evans, J., Heron, J. and Lewis, G. (2011) Cannabis, COMT and Psychotic Experiences. British Journal of Psychiatry, 199, 380-385.

https://doi.org/10.1192/bjp.bp.111.091421

[109] Costas, J., Sanjuán, J., Ramos-Rios, R., Paz, E., Agra, S., Tolosa, A., Paramo, M., Brenlla, J. and Arrojo, M. (2011) Interaction between COMT Halotypes and Cannabis in Schizophrenia: A Case-Only Study in Two Samples from Spain. Schizophrenia Research, 127, 22-27. https://doi.org/10.1016/j.schres.2011.01.014

[110] Van Winkel, R. and Genetic Risk and Outcome of Psychosis (GROUP) Investigators (2011) Family-Based Analysis of Genetic Variation Underlying Psychosis-Inducing Effects of Cannabis: Sibling Analysis and Proband Follow-Up. Archives of General Psychiatry, 68, 148-157.

https://doi.org/10.1001/archgenpsychiatry.2010.152

[111] Decoster, J., Van Os, J., Myin-Germeys, I., De Hert, M. and Van Winkel, R. (2012) Genetic Variation Underlying Psychosis-Inducting Effects of Cannabis: Critical Review and Future Directions. Current Pharmaceutical Design, 18, 5015-5023. https://doi.org/10.2174/138161212802884591

[112] De Sousa, K.R., Tiwan, A.K., Giuffra, D.E., Mackenzie, B., Zai, C.C. and Kennedy, J.L. (2013) Age at Onset of Schizophrenia: Cannabis, COMT Gene, and Their Interactions. Schizophrenia Research, 151, 289-290. https://doi.org/10.1016/j.schres.2013.10.037

[113] Henquet, C., Rosa, A., Krabbendam, L., Papiol, S., Fananás, L., Drukker, M., Ramaekers, J.G. and Van Os, J. (2006) An Experimental Study of Catechol-O-Methyltransferase Val 158 Met Moderation of 4 -9-Tetrahydrocannabinol-Induced Effects on Psychosis and Cognition. Neuropsychopharmacology, 31, 2748-2757.

https://doi.org/10.1038/sj.npp.1301197

[114] Henquet, C., Rosa, A., Delespaul, P., Papiol, S., Fananás, L. and Van Os, J. (2009) COMT Val Met Moderation of Cannabis-Induced Psychosis: A Momentary Assessment Study of Searching on Hallucinations in the Flow of Daily Life. Acta Psychiatrica Scandinavica, 119, 156-160.

https://doi.org/10.1111/j.1600-0447.2008.01265.x

[115] Savitz, J., Van Der Merwe, L., Newman, T.K., Stein, D.J. and Ramesar, R. (2010) Catechol-O-Methyltransferase Genotype and Childhood Trauma May Interact to Impact Schizotypal Personality Trails. Behavior Genetics, 40, 415-423. https://doi.org/10.1007/s10519-009-9323-7

[116] Estrada, G., Fatjo-Vilas, M., Muñoz, M.J., Pulido, G., Minano, M.J. and Toledo, E. (2011) Cannabis Use and Age at Onset of Psychosis: Further Evidence of Interaction with COMT Val 158 Met Polymorphism. Acta Psychiatrica Scandinavica, 123, 485-492. https://doi.org/10.1111/j.1600-0447.2010.01665.x

[117] Vinkers, C.H., Van Gastel, W.A., Schubart, C.D., Van Ejik, K.R., Luykx, J.J., Van Winkel, R., Joëls, M., Ophoff, R.A., Boks, M.P., Genetic Risk and Outcome of Psychosis (GROUP) Investigators, Bruggeman, R., Cahn, W., De Haan, L., Kahn, R.S., Meijer, C.J., Myin-Germeys, I., Van Os, J. and Wrersma, D. (2013) The Effect of Childhood Maltreatment and Cannabis Use on Adult Psychotic Symptoms Is Modified by the COMT Val ${ }^{158}$ Met Polymorphism. Schizophrenia Research, 150, 303-311. https://doi.org/10.1016/j.schres.2013.07.020

[118] Genetic Risk and Outcome in Psychosis (GROUP) Investigators (2011) Evidence That Familial Liability for Psychosis Is Expressed as Differential Sensitivity to Can- 
nabis. An Analysis of Patient-Sibling and Sibling-Control Pairs. Archives of General Psychiatry, 68, 138-147. https://doi.org/10.1001/archgenpsychiatry.2010.132

[119] Read, J., Van Os, J., Morrison, A.P. and Ross, C.A. (2005) Childhood Trauma, Psychosis and Schizophrenia: A Literature Review with Theoretical and Clinical Implications. Acta Psychiatrica Scandinavica, 112, 330-350. https://doi.org/10.1111/j.1600-0447.2005.00634.x

[120] Bendall, S., Jackson, H.J., Hulbert, C.A. and McGorry, P.D. (2008) Childhood Trauma and Psychotic Disorders: A Systematic, Critical Review of the Evidence. Schizophrenia Bulletin, 34, 568-579. https://doi.org/10.1093/schbul/sbm121

[121] Van Os, J., Kenis, G. and Rutten, B.P.F. (2010) The Environment and Schizophrenia. Nature, 468, 203-212. https://doi.org/10.1038/nature09563

[122] Di Forti, M., Lyegbe, C., Sallis, H., Kolliakou, A., Falcone, M.A., Paparelli, A., Sirianni, M., La Cascia, C., Stilo, S.A. and Marques, T.R. (2012) Confirmation That the AKT1 (rs 24944732) Genotype Influences the Risk of Psychosis in Cannabis Users. Biological Psychiatry, 72, 811-816. https://doi.org/10.1016/j.biopsych.2012.06.020

[123] Collizi, M., Lyegbe, C., Powell, J., Blasi, G., Bertolini, A., Murray, R.B. and Di Forti, M. (2015) Interaction between DRD2 and AKT1 Genetic Variations on Risk of Psychosis in Cannabis Users: A Case Control Study. NPJ Schizophrenia, 1, Article No. 15049. https://doi.org/10.1038/npjschz.2015.49

[124] Morgan, C.J.A., Freeman, T.P., Powell, J. and Curran, H.V. (2016) AKT1 Genotype Moderates the Acute Psychotomimetic Effects of Naturalistically Smoked Cannabis in Young Cannabis Smokers. Translational Psychiatry, 6, e738.

https://doi.org/10.1038/tp.2015.219

[125] Collizi, M., Lyegbe, C., Powell, J., Ursini, G., Porcelli, A., Bonvino, A., Taurisano, P., Romano, R., Masellis, R., Blasi G., Morgan, C., Aitchison, K., Mondelli, V., Luzi, S., Kolliakou, A., David, A., Murray, R.M., Bertolino, A. and Di Forti, M. (2015) Interaction between Functional Genetic Variation of DRD2 and Cannabis Use on Risk of Psychosis. Schizophrenia Bulletin, 4, 1171-1182.

https://doi.org/10.1093/schbul/sbv032

[126] Veling, W., Mackenback, J.P., Van Os, J. and Hock, H.W. (2008) Cannabis Use and Genetic Predisposition for Schizophrenia: A Case-Control Study. Psychological Medicine, 38, 1251-1256. https://doi.org/10.1017/S0033291708003474

[127] Hjorthoj, C., Uddin, M.J., Winberley, T., Dalsgaard, S., Hougard, D.M., Borglum, A., Werge, T. and Nordentoft, M. (2019) No Evidence of Associations between Genetic Liability for Schizophrenia and Development of Cannabis Use Disorder. Psychological Medicine, 1-6. https://doi.org/10.1017/S0033291719003362

[128] Janssen, I., Krabbendam, L., Bak, M. and Hanssen, M. (2004) Childhood Abuse as a Risk Factor for Psychotic Experiences. Acta Psychiatica Scandinavica, 109, 38-45. https://doi.org/10.1046/j.0001-690X.2003.00217.x

[129] Wicks, S., Hjern, A., Gunnell, D., Lewis, G. and Dalman, C. (2005) Social Adversity in Childhood and the Risk of Developing Psychosis: A National Cohort Study. American Journal of Psychiatry, 162, 1652-1657. https://doi.org/10.1176/appi.ajp.162.9.1652

[130] Morgan, C. and Fisher, H. (2007) Environmental Factors in Schizophrenia: Childhood Trauma. A Critical Review. Schizophrenia Bulletin, 33, 3-10. https://doi.org/10.1093/schbul/sbl053

[131] Shevlin, M., Dorahy, M.J. and Adamson, G. (2007) Trauma and Psychosis: An Analysis of the National Comorbidity Survey. American Journal of Psychiatry, 164, 
166-169. https://doi.org/10.1176/ajp.2007.164.1.166

[132] Matheson, S.L., Shepherd, A.M., Pinchbeck, R.M., Liurens, K.R. and Carr, V.J. (2013) Childhood Adversity in Schizophrenia: A Systematic Meta-Analysis. Psychological Medicine, 43, 225-238. https://doi.org/10.1017/S0033291712000785

[133] Bak, M., Krabbendam, L., Janssen, I., De Graaf, R., Vollebergh, W. and Van Os, J. (2005) Early Trauma May Increase the Risk for Psychotic Experiences by Impacting on Emotional Response and Perception of Control. Acta Psychiatrica Scandinavica, 112, 360-366. https://doi.org/10.1111/j.1600-0447.2005.00646.x

[134] Kelleher, I., Harley, M., Lynch, F., Arseneault, L., Fitzpatrick, C. and Cannon, M. (2008) Associations between Childhood Trauma, Bullying and Psychotic Symptoms among a School-Based Adolescent Sample. British Journal of Psychiatry, 193, 378-382. https://doi.org/10.1192/bjp.bp.108.049536

[135] Lardinois, M., Lataster, T., Mengelers, R., Van Os, J. and Myin-Germeys, I. (2011) Childhood Trauma and Increased Stress Sensitivity in Psychosis. Acta Psychiatrica Scandinavica, 123, 28-35. https://doi.org/10.1111/j.1600-0447.2010.01594.x

[136] Wigman, J.T., Van Winkel, R., Raaijmakers, O.A., Ormel, J., Verhulst, F.C., Reitneveld, S.A., Van Os, J. and Vollebergh, W.A. (2011) Evidence for a Persistent, Environment-Dependent and Deteriorating Subtype of Subclinical Psychotic Experiences: A 6-Year Longitudinal General Population Study. Psychological Medicine, 41, 2317-2329. https://doi.org/10.1017/S0033291711000304

[137] Varese, F., Smeets, F., Drukker, M., Lieverse, R., Lataster, T., Viechtbauer, W., Read, J., Van Os, J. and Bentall, R.P. (2012) Childhood Adversities Increase the Risk of Psychosis: A Meta-Analysis of Patient-Control, Prospective and Cross-Sectional Cohort Studies. Schizophrenia Bulletin, 38, 661-671.

https://doi.org/10.1093/schbul/sbs050

[138] Addington, J., Stowkowy, J., Cadenhead, K.S., Comblatt, B.A., McGlashan, T.H., Perkins, D.O., Seidman, I.J., Tsuang, M.T., Walker, E.F. and Woods, S.W. (2013) Early Traumatic Experiences in Those at Clinical High Risk for Psychosis. Early Intervention in Psychiatry, 7, 300-305. https://doi.org/10.1111/eip.12020

[139] Van Winkel, R., Van Nierop, M., Myin-Germeys, L. and Van Os, J. (2013) Childhood Trauma as a Cause of Psychosis: Linking Genes, Psychology, and Biology. Canadian Journal of Psychiatry, 58, 44-51. https://doi.org/10.1177/070674371305800109

[140] Thompson, A.D., Nelson, B., Yuen, H.P., Lin, A., Amminger, G.P., McGorry, P.D., Wood, S.J. and Yung, A.R. (2014) Sexual Trauma Increases the Risk of Developing Psychosis in an Ultra High-Risk "Prodomal" Population. Schizophrenia Bulletin, 40, 697-706. https://doi.org/10.1093/schbul/sbt032

[141] Schoeler, T., Monk, A., Sami, M.B., Klamerus, E., Foglia, E., Brown, R., Camuri, G., Altamura, A.C., Murray, R. and Battacharyya, S. (2016) Continued versus Discontinued Cannabis Use in Patients with Psychosis: A Systematic Review and Meta-Analysis. The Lancet Psychiatry, 3, 215-225. https://doi.org/10.1016/S2215-0366(15)00363-6

[142] De Bellis, M.D. (2002) Developmental Traumatology: A Contributory Mechanism for Alcohol and Substances Use Disorders. Psychoneuroendocrinology, 27, 155-170. https://doi.org/10.1016/S0306-4530(01)00042-7

[143] Gordon, H.W. (2002) Early Environmental Stress and Biological Vulnerability to Drug Abuse. Psychoneuroendocrinology, 27, 115-126. https://doi.org/10.1016/S0306-4530(01)00039-7

[144] Compton, M.T., Furman, A.C. and Kaslow, N.J. (2004) Lower Negative Symptom 
Scores among Cannabis-Dependent Patients with Schizophrenia-Spectrum Disorders: Preliminary Evidence from an African American First-Episode Sample. Schizophrenia Research, 71, 61-64. https://doi.org/10.1016/j.schres.2004.01.005

[145] Cornelius, J., Kirisci, L., Reynolds, M., Clark, D., Hayes, J. and Tarter, R. (2010) PTSD Contributes to Teen and Young Adult Cannabis Use Disorders. Addictive Behaviors, 35, 91-94. https://doi.org/10.1016/j.addbeh.2009.09.007

[146] Cougnard, A., Marcelis, M., Myin-Germeys, I., De Graaf, R., Volleburgh, W., Krabbendam, L., Leb, R., Wittchen, H.U., Henquet, C., Spauwen, J. and Van Os, J. (2007) Does Normal Developmental Expression of Psychosis Combine with Environmental Risk to Cause Persistence of Psychosis? A Psychosis Proneness-Persistence Model. Psychological Medicine, 37, S13-S27. https://doi.org/10.1017/S0033291706009731

[147] Houston, J.E., Murphy, J., Adamson, G., Stringer, M. and Shevlin, M. (2008) Childhood Sexual Abuse, Early Cannabis Use, and Psychosis: Testing an Interaction Model Based on the National Comorbidity Survey. Schizophrenia Bulletin, 34, 580-585. https://doi.org/10.1093/schbul/sbm127

[148] Shevlin, M., Murphy, J., Houston, J.E. and Adamson, G. (2009) Childhood Sexual Abuse, Early Cannabis Use, and Psychosis: Testing the Effects of Different Temporal Orderings Based on the National Comorbidity Survey. Psychological Social and Integrative Approaches, 1, 19-28. https://doi.org/10.1080/17522430802546640

[149] Harley, M., Kelleher, I., Clarke, M., Lynch, F., Arseneault, L., Connor, D., Fitzpatrick, C. and Cannon, M. (2010) Cannabis Use and Childhood Trauma Interact Additively to Increase the Risk of Psychotic Symptoms in Adolescence. Psychological Medicine, 40, 1627-1634. https://doi.org/10.1017/S0033291709991966

[150] Galetly, C., Van Hoff, M. and McFarlane, A. (2011) Psychotic Symptoms in Young Adults Exposed to Childhood Trauma. A 20 Year Follow-Up Study. Schizophrenia Research, 127, 76-82. https://doi.org/10.1016/j.schres.2010.12.010

[151] Houston, J.E., Murphy, J., Shevlin, M. and Adamson, G. (2011) Cannabis Use and Psychosis: Re-Visiting the Role of Childhood Trauma. Psychological Medicine, 41, 2339-2348. https://doi.org/10.1017/S0033291711000559

[152] Konings, M., Stefanis, N., Kuepper, R., De Graaf, R., Ten Have, M., Van Os, J., Bakoula, C. and Henquet, C. (2012) Replication in Two Independent Population-Based Samples That Childhood Maltreatment and Cannabis Use Synergistically Impact on Psychosis Risk. Psychological Medicine, 42, 149-159. https://doi.org/10.1017/S0033291711000973

[153] Voruganti, L.N., Slomka, P., Zabel, P., Mattar, A. and Awad, A.G. (2001) Cannabis Induced Dopamine Release: An In-Vivo SPECT Study. Psychiatry Research, 107, 173-177. https://doi.org/10.1016/S0925-4927(01)00104-4

[154] Soliman, A., O’Driscoll, G.A., Pruessner, J., Holahan, A.L., Boileau, I., Gagnon, D. and Dagher, A. (2008) Stress-Induced Dopamine Release in Humans at Risk of Psychosis: A [ $\left.{ }^{11} \mathrm{C}\right]$ Raclopride PET Study. Neuropsychopharmacology, 33, 2033-2041. https://doi.org/10.1038/sj.npp.1301597

[155] Bossong, M.G., Van Berckel, B.N., Boellaard, R., Zuurman, L., Schurt, R.C., Windhorst, A.D., Van Gerven, J.M., Ramsey, N.F., Lammertsma, A.A. and Kahn, R.S. (2009) Delta-9-Tetrahydrocannabinol Induces Dopamine Release in the Human Striatum. Neuropsychopharmacology, 34, 759-766.

https://doi.org/10.1038/npp.2008.138

[156] Collip, D., Myin-Germeys, L. and Van Os, J. (2008) Does the Concept of "Sensitization" Provide a Plausible Mechanism for the Putative Link between the Environment and Schizophrenia? Schizophrenia Bulletin, 34, 220-225. 
https://doi.org/10.1093/schbul/sbm163

[157] Dominguez, M.D., Wichers, M., Lieb, R., Wittchen, H.U. and Van Os, J. (2010) Evidence That Onset of Clinical Psychosis Is an Outcome of Progressively More Persistent Subclinical Psychotic Experiences: An 8-Year Cohort Study. Schizophrenia Bulletin, 37, 84-93. https://doi.org/10.1093/schbul/sbp022

[158] Murphy, J., Houston, J.E., Shevlin, M. and Adamson, G. (2013) Childhood Sexual Trauma, Cannabis Use and Psychosis: Statistically Controlling for Pre-Trauma Psychosis and Psychopathology. Social Psychiatry and Psychiatric Epidemiology, 48, 853-861. https://doi.org/10.1007/s00127-012-0592-8

[159] Van Nierop, M., Janssens, M., Genetic Risk Outcome of Psychosis (GROUP) Investigators, Bruggeman, R., Cahn, W., De Haan, L., Kahn, R.S., Meijer, C.J., Myin-Germeys, I., Van Os, J. and Wiersma, D. (2013) Evidence That Transition from Health to Psychotic Disorder Can Be Traced to Semi-Ubiquitous Environmental Effects Operating against Background Genetic Risk. PLoS ONE, 8, e76690. https://doi.org/10.1371/journal.pone.0076690

[160] Morgan, C., Reininghaus, U., Reichenberg, A., Frissa, S., SELCoH Study Team, Hotopf, M. and Hatch, S.L. (2014) Adversity, Cannabis Use and Psychotic Experiences: Evidence of Cumulative and Synergistic Effects. British Journal of Psychiatry, 204, 346-353. https://doi.org/10.1192/bjp.bp.113.134452

[161] Sideli, L., Fisher, H.L., Murray, R.M., Sallis, H., Russo, M., Stilo, S.A., Paparelli, A., Wiffen, B.D.R., O’Connor, J.A., Pintore, S., Ferraro, L., La Cascia, C., La Barbera, D., Morgan, C. and Di Forti, M. (2018) Interaction between Cannabis Consumption and Childhood Abuse in Psychotic Disorders: Preliminary Findings on the Role of Different Patterns of Cannabis Use. Early Intervention in Psychiatry, 12, 135-142. https://doi.org/10.1111/eip.12285

[162] Weiser, M., Reichenberg, A., Grotto, I., Yasvitzky, R., Rabinowitz, J., Lubin, G., Nahon, D., Knobler, H.Y. and Davidson, M. (2004) Higher Rates of Cigarette Smoking in Male Adolescents before the Onset of Schizophrenia: A Historical Prospective Cohort Study. American Journal of Psychiatry, 161, 1219-1223.

https://doi.org/10.1176/appi.ajp.161.7.1219

[163] Sørensen, H.J., Mortensen, E.L., Reinisch, J.M. and Mednick, S.A. (2011) A Prospective Study of Smoking in Young Women and Risk of Later Psychiatric Hospitalization. Nordic Journal of Psychiatry, 65, 3-8.

https://doi.org/10.3109/08039481003786386

[164] Van Gastel, W.A., MacCabe, J.H., Schubart, C.D., Vreeker, A., Tempelaar, W., Kahn, R.S. and Boks, M.P.M. (2013) Cigarette Smoking and Cannabis Use Are Equally Strongly Associated with Psychotic-Like Experiences: A Cross-Sectional Study in 1929 Young Adults. Psychological Medicine, 43, 2393-2401. https://doi.org/10.1017/S0033291713000202

[165] Hartz, S.M., Horton, A.C., Hancock, D.B., Baker, T.B., Caporaso, N.E., Chen, L.-S., Hokanson, J.E., Lutz, S.M., Marazita, M., McNeil, D., Pato, C, Pato, M., Johnson, E.O. and Bierut, L.T. (2018) Genetic Correlation between Smoking Behaviors and Schizophrenia. Schizophrenia Research, 194, 86-90. https://doi.org/10.1016/j.schres.2017.02.022

[166] Mustonen, A., Ahokas, T., Nordstreom, T., Murray, G.K., Mäki, P., Jääskelãinen, E., Heiskala, A., Megrath, J.J., Scott, J.G., Miettunen, J. and Niemelä, S. (2018) Smokin Hot: Adolescent Smoking and the Risk of Psychosis. Acta Psychiatrica Scandinavica, 138, 5-14. https://doi.org/10.1111/acps.12863

[167] Degenhardt, L., Hall, W. and Linskey, M. (2001) Alcohol, Cannabis and Tobacco 
Use among Australians: A Comparison of Their Associations with Other Drug Use and Use Disorders, Affective and Anxiety Disorders, and Psychosis. Addiction, 96, 1603-1614. https://doi.org/10.1046/j.1360-0443.2001.961116037.x

[168] Wiles, N.J., Zammit, S., Bebbington, P., Singleton, N., Meltzer, H. and Lewis, G. (2006) Self-Reported Psychotic Symptoms in the General Population: Results from the Longitudinal Study of the British National Psychiatric Morbidity Survey. British Journal of Psychiatry, 188, 519-526. https://doi.org/10.1192/bjp.bp.105.012179

[169] Lasser, K., Boyd, J.W., Woolhandler, S., Himmelstein, D.U., McCormick, D. and Bor, D.H. (2000) Smoking and Mental Illness: A Population-Based Prevalence Study. Journal of the American Medical Association, 284, 2606-2610.

https://doi.org/10.1001/jama.284.20.2606

[170] Ziedonis, D., Hitsman, B., Beckham, J.C., Zvolensky, M., Adler, L.E., Udrain-McGovern, J., Breslau, N., Brown, R.A., George, T.P., Williams, J., Calhoun, P.S. and Riley, W.T. (2008) Tobacco Use and Cessation in Psychiatric Disorders: National Institute of Mental Health Report. Nicotine and Tobacco Research, 10, 1691-1715. https://doi.org/10.1080/14622200802443569

[171] Saha, S., Scott, J.G., Varghese, D., Degenhardt, L., Slade, T. and McGrath, J.J. (2011) The Association between Delusional-Like Experiences, and Tobacco, Alcohol of Cannabis Use: A Nationwide Population-Based Survey. BMC Psychiatry, 11, 202-209. https://doi.org/10.1186/1471-244X-11-202

[172] Dean, B., Bymaster, F.P. and Scarr, E. (2003) Muscarinic Receptors in Schizophrenia. Current Molecular Medicine, 3, 419-426. https://doi.org/10.2174/1566524033479654

[173] Brody, A.L., Olmstead, R.E., London, E.D., Farahi, J., Meyer, J.H., Grossman, P., Lee, G.S., Huang, J., Hahn, E.L. and Mandelkern, M.A. (2004) Smoking-Induced Ventral Striatum Dopamine Release. American Journal of Psychiatry, 161, 1211-1218. https://doi.org/10.1176/appi.ajp.161.7.1211

[174] Ripoll, N., Bronnec, M. and Bourin, M. (2004) Nicotinic Receptors and Schizophrenia. Current Medical Research and Opinion, 10, 1057-1074. https://doi.org/10.1185/030079904125004060

[175] Dalack, G.W., Healy, D.J. and Meador-Woodruff, J.H. (1998) Nicotine Dependence in Schizophrenia: Clinical Phenomena and Laboratory Findings. American Journal of Psychiatry, 155, 1490-1591. https://doi.org/10.1176/ajp.155.11.1490

[176] Lyon, E.R. (1999) A Review of the Effects of Nicotine on Schizophrenia and Antipsychotic Medications. Psychiatric Services, 50, 1346-1350. https://doi.org/10.1176/ps.50.10.1346

[177] Punnoase, S. and Belgamwar, M.R. (2006) Nicotine for Schizophrenia. Cochrane Database of Systematic Reviews, No. 25, CD004838.

https://doi.org/10.1002/14651858.CD004838.pub2

[178] Barr, R.S., Culhane, M.A., Jubelt, L.E., Mufti, R.S., Dyer, M.A., Weiss, A.P., Deckersbach, T., Kelly, J.B., Freudenreich, O., Goff, D.C. and Evins, A.E. (2008) The Effects of Transdermal Nicotine on Cognition in Non-Smokers with Schizophrenia and Nonpsychiatric Controls. Neuropsychopharmacology, 33, 480-490. https://doi.org/10.1038/sj.npp.1301423

[179] Jubelt, L.E., Barr, R.S., Goff, D.C., Logvinenko, T., Weiss, A.P. and Evins, A.E. (2008) Effects of Transdermal Nicotine on Episodic Memory in Non-Smokers with and without Schizophrenia. Psychopharmacology, 199, 89-98. https://doi.org/10.1007/s00213-008-1133-8

[180] Wignall, N.D. and De Wit, H. (2011) Effects of Nicotine on Attention and Inhibi- 
tory Control in Healthy Nonsmokers. Experimental and Clinical Psychopharmacology, 19, 183-191. https://doi.org/10.1037/a0023292

[181] Compton, M.T., Kelley, M.E., Ramsay, C.E., Pringle, M., Goulding, S.M., Esterberg, M.L., Stewart, T. and Walker, E.F. (2009) Association of Pre-Onset Cannabis, Alcohol and Tobacco Use with Age at Onset of Prodrome and Age of Onset of Psychosis in First-Episode Patients. American Journal of Psychiatry, 166, 1251-1257. https://doi.org/10.1176/appi.ajp.2009.09030311

[182] Dalack, G.W. and Meador-Woodruff, J.H. (1996) Smoking, Smoking Withdrawal and Schizophrenia: Case Reports and a Review of the Literature. Schizophrenia Research, 22, 133-141. https://doi.org/10.1016/S0920-9964(96)80441-5

[183] Gage, S.H., Hickman, M., Heron, J., Munafo, M.R., Lewis, G., Macleod, J. and Zammit, S. (2014) Associations of Cannabis and Cigarette Use with Psychotic Experience at Age 18: Findings from the Avon Longitudinal Study of Parents and Children. Psychological Medicine, 44, 3435-3444. https://doi.org/10.1017/S0033291714000531

[184] Myles, N., Newall, H., Nielssen, O. and Large, M. (2012) The Association between Cannabis Use and Earlier Age at Onset of Schizophrenia and Other Psychosis: Meta-Analysis of Possible Confounding Factors. Current Pharmaceutical Design, 18, 5055-5069. https://doi.org/10.2174/138161212802884816

[185] Krabbendam, L. and Van Os, J. (2005) Schizophrenia and Urbanicity: A Major Environmental Influence-Conditional on Genetic Risk. Schizophrenia Bulletin, 31, 795-799. https://doi.org/10.1093/schbul/sbi060

[186] March, B., Hatch, S.I., Morgan, C., Kirkbride, J.B., Bresnahan, M., Fearon, P. and Susser, E. (2008) Psychosis and Place. Epidemiologic Review, 30, 84-100.

https://doi.org/10.1093/epirev/mxn006

[187] Kelly, B.D., O’Callaghan, E., Waddington, J.L., Feeney, L., Browne, S., Scully, P.J., Clarke, M., Quinn, J.F., McTigue, O., Morgan, M.G., Kinsella, A. and Larkin, C. (2010) Schizophrenia and the City: A Review of Literature and Prospective Study of Psychosis and Urbanicity in Ireland. Schizophrenia Research, 116, 75-89. https://doi.org/10.1016/j.schres.2009.10.015

[188] Van Os, J., Hanssen, M., Bak, M., Bijl, R.V. and Vollebergh, W. (2003) Do Urbanicity and Familial Liability Coparticipate in Causing Psychosis? American Journal of Psychiatry, 160, 477-482. https://doi.org/10.1176/appi.ajp.160.3.477

[189] Weiser, M., Van Os, J., Reichenberg, A., Rabinowitz, J., Nahon, D., Kravitz, E., Lubin, G., Schmushkevitz, M., Knobler, H.Y., Noy, S. and Davidson, M. (2007) Social and Cognitive Functioning, Urbanicity and Risk for Schizophrenia. British Journal of Psychiatry, 191, 320-324. https://doi.org/10.1192/bjp.bp.106.031328

[190] Van Winkel, R., Stefanis, N.C. and Myin-Germeys, I. (2008b) Psychosocial Stress and Psychosis. A Review of the Neurobiological Mechanisms and the Evidence for Gene-Stress Interaction. Schizophrenia Bulletin, 34, 1095-1105. https://doi.org/10.1093/schbul/sbn101

[191] DeVylder, J.E., Kelleher, I., Lafane, M., Oh, H., Link, B.G. and Koyanagi, A. (2018) Association of Urbanicity with Psychosis in Low-and-Middle-Income Countries. JAMA Psychiatry, 75, 678-686. https://doi.org/10.1001/jamapsychiatry.2018.0577

[192] Kuepper, R., Van Os, J., Lieb, R., Wittchen, H.U. and Henquet, C. (2011) Do Cannabis and Urbanicity Co-Participate in Causing Psychosis? Evidence from a 10-Year Follow-Up Cohort Study. Psychological Medicine, 41, 2121-2129. https://doi.org/10.1017/S0033291711000511

[193] Scatton, B. and Sanger, D.J. (2000) Pharmacological and Molecular Targets in the 
Search for Novel Antipsychotics. Behavioral Pharmacology, 11, 243-256. https://doi.org/10.1097/00008877-200006000-00008

[194] Eggan, S.M., Hashimoto, T. and Lewis, D.A. (2008) Reduced Cortical Cannabinoid 1 Receptor Messenger RNA and Protein Expression in Schizophrenia. Archives of General Psychiatry, 65, 772-784. https://doi.org/10.1001/archpsyc.65.7.772

[195] Renard, J., Norris, C., Rushlow, W. and Laviolette, S.R. (2017) Neuronal and Molecular Effects of Cannabidiol on the Mesolimbic Dopamine System: Implications for Novel Schizophrenia Treatments. Neuroscience and Biobehavioral Review, 75, 157-165. https://doi.org/10.1016/j.neubiorev.2017.02.006

[196] Hahn, B. (2018) The Potential of Cannabidiol Treatment for Cannabis Users with Recent-Onset Psychosis. Schizophrenia Bulletin, 44, 46-53.

https://doi.org/10.1093/schbul/sbx105

[197] Scuderi, C., De Filippis, D., Iuvone, T., Blasio, A., Steardo, A. and Esposito, G. (2009) Cannabidiol in Medicine: A Review of Its Therapeutic Potential in CNS Disorders. Phytotherapy Research, 23, 597-602. https://doi.org/10.1002/ptr.2625

[198] Rohleder, C., Müller, J.K., Lange, B. and Leweke, F.M. (2016) Cannabidiol as a Potential New Type of an Antipsychotic. A Critical Review of the Evidence. Frontiers in Pharmacology, 7, 422. https://doi.org/10.3389/fphar.2016.00422

[199] Trimbos, T.N.I. (2009) THC-concentraties in wiet, nederwiet en hasj in Nederlands coffeeshops. 1-1-2009. Ref Type: Generic.

[200] Hardwick, S. and King, L.A. (2008) Home Office Cannabis Potency Study 2008. United Kingdom, Home Office Scientific Development Branch, 16 p.

[201] Morgan, C.J.A., Gardener, C., Schafer, G., Swan, S., Demarchi, C., Freeman, T.P., Warrington, P., Rupasinghe, I., Ramoutar, A., Tan, N., Wingham, G., Lewis, S. and Curran, H.V. (2012) Sub-Chronic Impact of Cannabinoids in Street Cannabis on Cognition, Psychotic-Like Symptoms and Psychological Well-Being. Psychological Medicine, 42, 391-400. https://doi.org/10.1017/S0033291711001322

[202] Mechoulam, R. and Shvo, Y. (1963) Haschich. I. The Structure of Cannabidiol. Tetrahedron, 19, 2073-2078. https://doi.org/10.1016/0040-4020(63)85022-X

[203] Thomas, A., Baillie, G.L., Phillips, A.M., Razdan, R.K., Ross, R.A. and Pertwee, R.G. (2007) Cannabidiol Displays Unexpectedly High Potency as an Antagonist of CB1 and CB2 Receptor Agonists in Vitro. British Journal of Pharmacology, 150, 613-623. https://doi.org/10.1038/sj.bjp.0707133

[204] Rottanburg, D., Robins, A.H., Ben-Arie, O., Teggin, A. and Elk, R. (1982) Cannabis-Associated Psychosis with Hypomanic Features. The Lancet, 2, 1364-1366. https://doi.org/10.1016/S0140-6736(82)91270-3

[205] Zuardi, A.W., Shirakawa, I., Finkelfarb, E. and Karniol, I.G. (1982) Action of Cannabidiol on the Anxiety and Other Effects Produced by Delta 9-THC in Normal Subjects. Psychopharmacology, 76, 245-250. https://doi.org/10.1007/BF00432554

[206] Russo, E. and Guy, G.W. (2006) A Tale of Two Cannabinoids: The Therapeutic Rationale for Combining Tetrahydrocannabinol and Cannabidiol. Medical Hypotheses, 66, 234-246. https://doi.org/10.1016/j.mehy.2005.08.026

[207] Bhattacharyya, S., Morrison, P.D., Fusar-Poli, P., Martin-Santos, R., Borgwardi, S., Winton-Brown, T., Nosarti, C., O’Carroll, C.M., Seal, M., Allen, P., Mehta, M., Stone, J.M., Tunstall, N., Giampietro, V., Kapur, S., Murray, R.M., Zuardi, A.W., Crippa, J.A., Atakan, Z. and McGuire, P.K. (2010) Opposite Effects of Delta-9-Tetrahydrocannabinol and Cannabidiol on Human Brain Function and Psychopathology. Neuropsychopharmacology, 35, 764-774. 
https://doi.org/10.1038/npp.2009.184

[208] Zuardi A.W., Morais, S.L., Guimarães, F.S. and Mechoulam, R. (1995) Antipsychotic Effect of Cannabidiol. The Journal of Clinical Psychiatry, 56, 485-486.

[209] Zuardi, A.W., Crippa, J.A., Hallak, J.E., Moreira, F.A. and Guimarães, F.S. (2006) Cannabidiol, a Cannabis Sativa-Constituent, as an Antipsychotic Drug. Brazilian Journal of Medical and Biological Research, 39, 421-429. https://doi.org/10.1590/S0100-879X2006000400001

[210] Zuardi, A.W., Hallak, J.E., Dursun, S.M., Morais, S.L., Faria Sanchez, R.F., Musty, R.E. and Crippa, J.A. (2006) Cannabidiol Monotherapy for Treatment-Resistant Schizophrenia. Journal of Psychopharmacology, 20, 683-686.

https://doi.org/10.1177/0269881106060967

[211] Leweke, F.M., Schneider, U., Radwan, M., Schmidt, E. and Emrich, H.M. (2000) Different Effects of Nabilone and Cannabidiol on Binocular Depth Inversion in Man. Pharmacology Biochemistry and Behavior, 66, 175-181. https://doi.org/10.1016/S0091-3057(00)00201-X

[212] Morgan, C.J. and Curran, H.V. (2008) Effects of Cannabidiol on Schizophrenia-Like Symptoms in People Who Use Cannabis. British Journal of Psychiatry, 192, 306-307. https://doi.org/10.1192/bjp.bp.107.046649

[213] McGuire, P., Robson, P., Cubala, W.J., Vasile, D., Morrison, P.D., Barron, R., Taylor, A. and Wright, S. (2018) Cannabidiol (CBD) as an Adjunctive Therapy in Schizophrenia: A Multicentre Randomized Controlled Trial. American Journal of Psychiatry, 175, 225-231. https://doi.org/10.1176/appi.ajp.2017.17030325

[214] Hudson, R., Renard, J., Norris, C., Rushlow, W.J. and Lanolette, S.R. (2019) Cannabidiol Courteracts the Psychotropic Side-Effects of 9-Tetrahydrocannabinol in the Ventral Hippocampus through Bidirectional Control of ERK 1-2 Phosphorylation. Journal of Neuroscience, 39, 8762-8777. https://doi.org/10.1523/JNEUROSCI.0708-19.2019

[215] Smith, N. (2005) High Potency Cannabis: The Forgotten Variable. Addiction, 100, 1558-1560. https://doi.org/10.1111/j.1360-0443.2005.01295.x

[216] King, L. (2008) Understanding Cannabis Potency and Monitoring Cannabis Products in Europe. In: Sznitman, S.R., Olsson, B. and Room, R., Eds., A Cannabis Reader. Global Issues and Local Experiences. Monograph, Vol. 1. European Monitoring Centre for Drugs and Drug Addiction, Lisbon, 242-259.

[217] McLaren, J., Swift, W., Dillon, P. and Allsop, S. (2008) Cannabis Potency and Contamination: A Review of the Literature. Addiction, 103, 1100-1109. https://doi.org/10.1111/j.1360-0443.2008.02230.x

[218] Zuardi, A.W., Rodrigues, J.A. and Cunha, J.M. (1991) Effects of Cannabidiol in Animal Models Predictive of Antipsychotic Activity. Psychopharmacology, 104, 260-264. https://doi.org/10.1007/BF02244189

[219] Di Forti, M., Morgan, C., Dazzan, P., Pariante, C., Mondelli, V.M., Marques, T.R., Handley, R., Luzi, S., Russo, M., Paparelli, A., Butt, A., Stilo, S.A., Wiffen, B., Powell, J. and Murray, R.M. (2009) High Potency Cannabis and the Risk of Psychosis. British Journal of Psychiatry, 195, 488-491. https://doi.org/10.1192/bjp.bp.109.064220

[220] Schubart, C.D., Sommer, J.E.C., Van Gastel, W.A., Goetgebuer, R.L., Kahn, R.S. and Boks, M.P.M. (2011) Cannabis with High Cannabidiol Content Is Associated with Fewer Psychotic Experiences. Schizophrenia Research, 130, 216-221. https://doi.org/10.1016/j.schres.2011.04.017

[221] Campos, A.C., Fogaça, M.V., Sonego, A.B. and Guimarães, F.S. (2016) Cannabidiol, 
Neuroprotection and Neuropsychiatric Disorders. Pharmacology Research, 112, 119-127. https://doi.org/10.1016/j.phrs.2016.01.033

[222] Bergamaschi, M.M., Queiroz, R.H., Chagas, M.H., De Oliveira, D.C., De Martinis, B.S., Kapczinski, F., Quevedo, J., Roesler, R., Schröder, N., Nardi, A.E., Martin-Santos, R., Hallak, J.E., Zuardi, A.W. and Crippa, J.A. (2011) Cannabidiol Reduces the Anxiety Patients. Neuropsychopharmacology, 35, 1219-1226.

https://doi.org/10.1038/npp.2011.6

[223] Crippa, J.A., Derenusson, G.N., Ferrari, T.B., Wichert, A.L., Duran, F.L., Martín-Santos, R., Simöes, M.V., Battacharyya, S., Fusar-Poli, P., Atakan, Z., Santos Filho, A., Freitas-Ferrari, M.C., McGuire, P.K., Zuardi, A.W., Busatto, G.F. and Hallak, J.E. (2011) Neural Basis of Anxiolytic Effects of Cannabidiol (CBD) in Generalized Social Anxiety Disorder: A Preliminary Report. Journal of Psychopharmacology, 25, 121-130. https://doi.org/10.1177/0269881110379283

[224] Fakkoury, M. (2016) Could Cannabidiol Be Used as an Alternative to Antipsychotics? Psychiatry Research, 80, 14-21.

[225] Leweke, F.M., Piomelli, D., Pahlisch, F., Muhl, D., Gerth, C.W., Hoyer, C., Klosterkötter, J., Hellmich, M. and Koethe, D. (2012) Cannabidiol Enhances Anandamide Signaling and Alleviates Psychotic Symptoms of Schizophrenia. Translational Psychiatry, 2, e94. https://doi.org/10.1038/tp.2012.15

[226] Khoury, J.M., Neves, M.C., Roque, M.A., Queiroz, D.A., De Freitas, A.A., De Fátima, A., Moreira, F. and Garcia, F.D. (2017) Is There a Role for Cannabidiol in Psychiatry? World Journal of Biological Psychiatry, 23, 1-34.

[227] Tien, A.Y. and Anthony, J.C. (1990) Epidemiological Analysis of Alcohol and Drug Use and Risk Factors for Psychotic Experiences. Journal of Nervous and Mental Disease, 178, 473-480. https://doi.org/10.1097/00005053-199008000-00001

[228] Degenhardt, L., Ferrari, A.J., Calabria, B., Hall, W.D., Norman, R.E., McGrath, J., Flaxman, A.D., Engell, R.E., Freedman, G.D., Whiteford, H.A. and Vos, T. (2013) The Global Epidemiology and Contribution of Cannabis Use and Dependence to the Global Burden of Disease: Results from the GBD 2010 Study. PLoS ONE, 8, e76635. https://doi.org/10.1371/journal.pone.0076635

[229] Giedd, J.N., Blumenthal, J., Jeffries, N.O., Castellanos, F.X., Liu, H., Zijdenbos, A., Pano, J., Evans, A.C. and Rapoport, J.L. (1999) Brain Development during Childhood and Adolescence: A Longitudinal MRI Study. Nature Neuroscience, 2, 861-863. https://doi.org/10.1038/13158

[230] Cannon, M., Harley, M., Clarke, M.C. and Arseneault, L. (2006) Genes, Cannabis and Psychosis. In: MacCabe, J., O’Daly, O., Murray, R.M., McGuffin, P. and Wright, P., Eds., Beyond Nature and Nurture in Psychiatry: Genes, Environment and Their Interplay, Ch. 16, Informa U.K. Ltd., Abingdon, 141-155. https://doi.org/10.1201/b14457-17

[231] Jacobus, J. and Tapert, S.F. (2014) Effects of Cannabis on the Adolescent-Brain. Current Pharmaceutical Design, 20, 2186-2193. https://doi.org/10.2174/13816128113199990426

[232] Silins, E., Horwood, L.J., Patton, G.C., Fergusson, D.M., Olson, C.A., Hutchinson, D.M., Spry, E., Toumbourou, J.W., Degenhardt, L., Swift, W., Coffey, C., Tait R.J., Letcher, P., Copeland, J. and Mattick, R.P. (2014) Young Adult Sequelae of Adolescent Cannabis Use: An Integrative Analysis. The Lancet Psychiatry, 1, 286-293. https://doi.org/10.1016/S2215-0366(14)70307-4

[233] Lubman, D.I., Cheetham, A. and Yucel, M. (2015) Cannabis and Adolescent Brain Development. Pharmacology and Therapeutics, 148, 1-16. 
https://doi.org/10.1016/j.pharmthera.2014.11.009

[234] Read, J., Perry, B.D., Moskowitz, A. and Connolly, J. (2001) The Contribution of Early Traumatic Events to Schizophrenia in Some Patients: A Traumagenic Neurodevelopmental Model. Psychiatry, 64, 319-345.

https://doi.org/10.1521/psyc.64.4.319.18602

[235] Frisher, M., Crome, I., Martino, O. and Croft, P. (2009) Assessing the Impact of Cannabis Use on Trends in Diagnosed Schizophrenia in the United Kingdom from 1996 to 2005. Schizophrenia Research, 113, 123-128.

https://doi.org/10.1016/j.schres.2009.05.031

[236] Hall, W. and Degenhardt, L. (2000) Cannabis Use and Psychosis: A Review of Clinical and Epidemiological Evidence. Australian and New Zealand Journal of Psychiatry, 39, 26-34. https://doi.org/10.1046/j.1440-1614.2000.00685.x

[237] Carney, R., Cotter, J., Firth, J., Bradshaw, T. and Yung, A.R. (2017) Cannabis Use and Symptom Severity in Individuals at Ultra High Risk for Psychosis: A Meta-Analysis. Acta Psychiatrica Scandinavica, 136, 5-15.

https://doi.org/10.1111/acps.12699

[238] Van Os, J., Verkooyen, R., Hendriks, M., Henquet, C., Bak, M., Marcelis, M., Delespaul, P., Krabbendam, L. and Myin-Germeys, I. (2008) A Psychosis Proneness-Persistence-Impairment Model of Psychotic Disorders. Tijdschrift Voor Psychiatrie, 50, 77-83.

[239] Power, R.A., Verweig, K.J.H., Zuhair, M., Montgomery, G.W., Henders, A.K., Health, A.C., Madden, P.A.F., Medland, S.E., Wray, N.R. and Martin, N.G. (2014) Genetic Predisposition to Schizophrenia Associated with Increased Use of Cannabis. Molecular Psychiatry, 19, 1201-1204. https://doi.org/10.1038/mp.2014.51

[240] Shakoor, S., Zavos, H.M.S., McGuire, P., Cardno, A.G., Freeman, D. and Ronald, A. (2015) Psychotic Experiences Are Linked to Cannabis Use in Adolescents in the Community Because of Common Underlying Environmental Risk Factors. Psychiatry Research, 227, 144-151. https://doi.org/10.1016/j.psychres.2015.03.041

[241] Connell, M., Betts, K., McGrath, J.J., Alati, R., Najmar, J., Clavarino, A., Mamun, A., Williams, G. and Septh, J.G. (2016) Hallucinations in Adolescents and Risk for Mental Disorders and Suicidal Behaviour in Adulthood: Prospective Evidence from the MSUP Birth Cohort Study. Schizophrenia Research, 176, 546-551.

https://doi.org/10.1016/j.schres.2016.06.009

[242] Hiemstra, M., Nelemans, S.A., Branje, S., Van Eijk, K.R., Hottenga, J.J., Vinkers, C.H., Van Lier, P., Meeus, W. and Boks, M.P. (2018) Genetic Vulnerability to Schizophrenia Is Associated with Cannabis Use Patterns during Adolescence. Drug and Alcohol Dependence, 190, 143-150.

https://doi.org/10.1016/j.drugalcdep.2018.05.024

[243] Leweke, F.M., Gerth, C.W. and Klosterkötter, J. (2004) Cannabis-Associated Psychosis. Current Status of Research. CNS Drugs, 18, 895-910.

https://doi.org/10.2165/00023210-200418130-00005

[244] Semple, D.M., McIntosh, A.M. and Lawrie, S.M. (2005) Cannabis as a Risk Factor for Psychosis: Systematic Review. Journal of Psychopharmacology, 19, 187-194. https://doi.org/10.1177/0269881105049040

[245] Atakan, Z. (2004) Cannabis and Psychosis: How Important Is the Link? Addiction, 99, 513-515. https://doi.org/10.1111/j.1360-0443.2004.00697.x 